NBER WORKING PAPER SERIES

\title{
THE BEHAVIORALIST GOES DOOR-TO-DOOR: UNDERSTANDING HOUSEHOLD TECHNOLOGICAL DIFFUSION USING A THEORY-DRIVEN NATURAL FIELD EXPERIMENT
}

\author{
Matilde Giaccherini \\ David H. Herberich \\ David Jimenez-Gomez \\ John A. List \\ Giovanni Ponti \\ Michael K. Price \\ Working Paper 26173 \\ http://www.nber.org/papers/w26173
}

\author{
NATIONAL BUREAU OF ECONOMIC RESEARCH \\ 1050 Massachusetts Avenue \\ Cambridge, MA 02138 \\ August 2019
}

\begin{abstract}
We would like to thank the Sloan Foundation for providing funding. David Jimenez-Gomez and Giovanni Ponti acknowledge additional financial support from the Spanish Ministry of Economics and Competitiveness (ECO2015-65820-P) and Generalitat Valenciana (Research Projects Gruposo3/086). We would also like to thank Noah Goldstein for his insightful discussions, Hendrik Wolff for his helpful comments and the research assistants at the Becker Center for their diligent assistance. This paper was previously circulated under the title: "How Many Economists Does it Take to Change a Light Bulb." The views expressed herein are those of the authors and do not necessarily reflect the views of the National Bureau of Economic Research or those of Maqueta, Inc.
\end{abstract}

NBER working papers are circulated for discussion and comment purposes. They have not been peer-reviewed or been subject to the review by the NBER Board of Directors that accompanies official NBER publications.

(C) 2019 by Matilde Giaccherini, David H. Herberich, David Jimenez-Gomez, John A. List, Giovanni Ponti, and Michael K. Price. All rights reserved. Short sections of text, not to exceed two paragraphs, may be quoted without explicit permission provided that full credit, including (C) notice, is given to the source. 
The Behavioralist Goes Door-To-Door: Understanding Household Technological Diffusion Using a Theory-Driven Natural Field Experiment

Matilde Giaccherini, David H. Herberich, David Jimenez-Gomez, John A. List, Giovanni

Ponti, and Michael K. Price

NBER Working Paper No. 26173

August 2019

JEL No. D9,D91

\begin{abstract}
This paper uses a field experiment to estimate behavioral parameters from a structural model of residential adoption of technology. As our model includes both economic and psychological factors, we are able to identify the role of prices, social norms, social pressure, and curiosity on the adoption decision. We find that prices and social norms influence the adoption decision along different margins, opening up the opportunity for economics and psychology to be strong complements in the diffusion process. In addition, welfare estimates from our structural model point to important household heterogeneities: whereas some consumers welcome the opportunity to purchase and learn about the new technology, for others the inconvenience and social pressure of the ask results in negative welfare. As a whole, our findings highlight that the design of optimal technological diffusion policies will require multiple instruments and a recognition of individual household heterogeneities.
\end{abstract}

Matilde Giaccherini

Centre for Economic and International Studies

Università degli Studi di Roma Tor Vergata

Via Columbia 2

00133 Roma

Italy

matilde.giaccherini@uniroma2.it

David H. Herberich

Marqeta, Inc.

180 Grand Ave

Oakland, CA 94612

dherberich@gmail.com

David Jimenez-Gomez

Department of Economics

University of Alicante

Spain

davidjimenezgomez@ua.es
John A. List

Department of Economics

University of Chicago

1126 East 59th

Chicago, IL 60637

and NBER

jlist@uchicago.edu

Giovanni Ponti

Departamento de Fundamentos del

Análisis Económico

Universidad de Alicante

03071 Alicante

Spain

giuba@ua.es

Michael K. Price

Department of Economics, Finance, and Legal Studies

The University of Alabama

250 Alston Hall

Box 870224

Tuscaloosa, AL 35487

and NBER

mkprice2@cba.ua.edu

A randomized controlled trials registry entry is available at H09367 
"Innovation is the market introduction of a technical or organisational novelty, not just its invention" Joseph Schumpeter

\section{Introduction}

Economists have long argued that an essential driver of economic growth is innovation (see, e.g. Romer, 1990; Aghion and Howitt, 1992). Indeed, in his seminal work, Young (2005) argues that differences in production technologies represent an important source of contrasting economic growth across countries historically. Indeed, some estimates suggest that roughly 50 percent of U.S. annual GDP growth can be attributed to innovation (U.S. Chamber of Commerce Foundation, 2012) ${ }^{1}$ As a result, policymakers have focused their efforts on designing policies that stimulate innovation, ranging from early childhood education programs to favorable tax treatment to subsidized investments in RD. The prevailing wisdom is that such public policies will increase development and application of ideas and technologies that improve goods and services, leading to economic growth.

Yet, what is often left on the sidelines in these discussions is the diffusion of new technologies. As Schumpeter's quote in the epigraph suggests, innovation is not only creation, but also market diffusion. For their part, economists, social scientists, and marketers have explored technological diffusion to varying degrees. Griliches (1957), for example, provides an early demonstration of the economic approach when he explored the adoption of hybrid corn technologies. In his analysis, Griliches focuses on two fundamental drivers of behavior: the pecuniary cost and benefits of the technology. ${ }^{2}$ Although economists highlight profit as the main motivation for technology adoption, other disciplines focus on non-pecuniary influences such as the influence of social networks and agents of change as underlying drivers of the adoption decision (e.g. Rogers, 2010). The differing viewpoints fostered a lively academic debate between sociologists and economists that remains a common reference today (see Skinner and Staiger (2007) for a recent addition to the discussion).

Since this early debate, economists have broadened their focus to explore non-pecuniary aspects of technology adoption (see, e.g. the excellent survey by Hall, 2004). An example of this exploration is the number of recent studies considering how social pathways influence adoption. The aim of this body of work is to explore how information is passed through societies or social networks and to identify how it affects subsequent adoption decisions (e.g. Bandiera and Rasul, 2006; Oster and Thornton, 2012; Chen et al., 2010;

\footnotetext{
${ }^{1}$ Similar figures on the importance of research intensity on annual GDP growth are reported in Fernald and Jones (2014) and Jones (2002).

${ }^{2}$ Foster and Rosenzweig (2010) and Jaffe et al. (2002) contain broader overviews of research on technology adoption.
} 
Conley and Udry, 2010).

In this paper, we take an alternate approach to the problem and design a theory-driven field experiment to explore the underlying economic and psychological factors that motivate technological adoption at the household level. As a case study, we use the purchase of an energy efficient technology - compact flourescent lightbulbs (CFLs). ${ }^{3}$ While CFLs offer substantial energy savings, residential consumers have been loathe to adopt them as an alternative to traditional incandescent bulbs. For example, even though 86 percent of households in the United States report using at least one energy-efficient light bulb, incandescent bulbs are contained in approximately 60 percent of all light sockets in homes in the United States (EPA, 2017). ${ }^{4}$

Our experimental design and subsequent empirical analysis is guided by a theoretical model much in the spirit of DellaVigna et al. (2012, DLM hereafter). Specifically, we model decisions as a multi-stage game with incomplete information in which consumers interact with their future selves. We extend the basic DLM framework to include three distinct motivations underlying the adoption of green technologies: 1) utility directly derived from CFLs (which is a combination of private returns and altruism), 2) social pressure or a desire to conform with the actions of others, and 3) curiosity, or the desire to seek information about energy efficient technologies. To recover the key parameters of our model, we employ an alternative structural estimation technique, namely, a Random Preference Probit (RPP) model (Hausman and Wise, 1976; Train, 1998). In doing so, our approach allows for correlation among the "random" components of utility (i.e., social pressure and curiosity) and, as a by-product, the explicit allowance for variation in tastes across individuals for the attributes of alternatives. Allowing for correlation across the structural components of our subjects' utilities seems an important step in the direction of realism as reduced form results suggest correlations across actions taken by the same individuals at different stages of the decision-making process.

In our field experiment, we approached nearly 9,000 households in the suburbs of Chicago, IL. Households were offered the opportunity to purchase either one or two packages that contained four CFLs. As in DLM, a crucial aspect of our experimental design is the ability of households to sort in or out of the face-to-face interaction with the salesperson. To operationalize this idea, we use warning flyers placed on door knobs of households to identify whether purchases are driven by the valuation for CFLs or social pressures. The flyers also allow us to identify heterogeneity and simulate how sorting impacts the effectiveness of our policy instruments. Additional randomization varies both the price at which households could purchase CFLs and the framing of a descriptive norm detailing the proportion of households in an area that report having at

\footnotetext{
${ }^{3}$ We focus on CFLs as lighting accounted for approximately 9 percent of total electricity consumption in the residential sector in the United States in 2017 and an even larger share of total electricity consumption in the residential sector worldwide.

${ }^{4}$ For perspective on the potential savings foregone, if every household in the United States were to install CFLs in the five most frequently used light fixtures it would; (i) save enough energy to light 23 million homes for a year, (ii) save nearly \$3.5billion in energy costs, and (iii) prevent greenhouse gas emissions equivalent to 4.1 million cars (EPA, 2017).
} 
least one CFL in their home. Our framing treatments test the importance of social pressure on purchase decisions and allow us to calculate an associated social norm elasticity of demand. ${ }^{5}$

We use data from the experiment to estimate reduced form and structural models that identify both the motives underlying the adoption decision and the distribution of reservation values. In addition, we use the structural model to simulate the effectiveness of two popular policy instruments - (i) a subsidy that serves to lower the price of purchasing the technology, and (ii) the use of a descriptive social norm detailing the proportion of households in a given area that report having at least one CFL in their home.

Data from our field experiment provide insights in three distinct areas. First, we find that both prices and descriptive social norms impact the adoption decision. Conditional on answering the door, households are approximately 8.7 percentage points (or 40 percent) less likely to purchase a package of CFLs at our high $(\$ 5)$ price level. Social norms have also a significant impact -although less pronounced-impact on purchase decisions. Conditioned on answering the door, households in our social norm treatments are approximately 3.5 percentage points (or 43 percent) more likely than counterparts in our neutral frame treatment to purchase at least one packet of CFLs. We find no discernible difference in the effect of our normative statements based on the proximity between the consumer and reference group.

Interestingly, we find that prices and descriptive norms influence behavior along different margins. Social norm statements affect behavior largely along the extensive margin. In fact, there is no discernible difference in the likelihood that a household in a social norm treatment purchases a second package of light bulbs relative to counterparts in a Neutral frame treatment. Prices, in contrast, affect behavior along both the intensive and the extensive margin. Indeed, households offered CFLs at $\$ 5$ per package are 52.5 percent less likely to purchase a second package than counterparts who can purchase CFLs at $\$ 1$ per package. To the best of our knowledge, we are the first to show that norms and prices are complements in the adoption decision. ${ }^{6}$ If this is a general insight, then the possibilities are limitless for the policymaker to enhance adoption decisions of households by combining economic and non-economic instruments.

A second major area of results involves sorting. Our warning treatments highlight the dual role of sorting in the adoption dynamics. On the one hand, flyers lower the frequency with which households answer the door. Whereas 36.7 percent of households approached in our No Warning treatment open the door, the fraction of households opening the door is approximately 6.4 percentage points (or 17.4 percent) lower in

\footnotetext{
${ }^{5}$ As noted in prior work, the descriptive social norm statements could influence the decision to purchase through at least two different channels. As in a Becker household production model, the information could be used to update prior beliefs concerning the benefits of the technology. Alternately, descriptive social norms could operate through conformity motivations or increased social pressures (e.g Lapinski and Rimal, 2005; Cialdini, 2007; Schultz et al., 2007; Ferraro and Price, 2013).

${ }^{6}$ The closest analog to this finding is Holladay et al. (2019) who show that while social comparisons and rebates impact the likelihood a households completes and in-home energy audit, neither policy has a significant impact on the likelihood of installing energy efficient technologies following the audit.
} 
our warning (i.e., Warning plus Opt-Out) treatments, respectively. This evidence is consistent with the idea that warned households lower the frequency of door opening in the attempt to avoid interacting with our salespeople and the resulting pressure to purchase a CFL. Alternatively, conditional on answering the door, households in our warning treatments are significantly more likely to purchase at least one package of CFLs. Households are approximately 2.2 percentage points (or 25 percent) more likely than counterparts in No Warning to purchase at least one pack of CFLs. This evidence confirms the idea that the warning treatments alter the distribution of types who answer the door towards those with a greater preference for (valuation of) CFLs.

Finally, the third area of results derives from the structural model. Our structural estimations refine the descriptive analysis by providing quantitative assessments of the motivating forces behind consumption decisions, and allow us to conduct policy counterfactuals exploring various ways to promote the adoption of CFLs. We find that both our estimated "curiosity" and "social pressure" are negative, although only the former is significant. A negative value of curiosity means that households prefer to avoid the interaction with the solicitors irrespectively of their purchase decisions, i.e., households dislike the interaction with solicitors per se, indicating strong a priori feelings of suspicion or a disinterest in learning about energy efficiency.

Our "random preference" approach model also reveals interesting household heterogeneities. For example, we discover that curiosity and social pressure are highly negatively correlated, indicating that those who are the more willing to interact with solicitors are also the ones less concerned about not purchasing. ${ }^{7}$ In addition, estimates from our structural model allow us to recover the distribution of CFL valuations, whose mean is just above $\$ 2$ per pack. Yet, our estimates for the distribution of willingness to pay suggest that a substantial fraction of individuals value CFLs less than the prevailing market price at the time of the experiment. In fact, more than three-quarters of all individuals appear to dislike CFLs and would require compensation in order to accept a package of CFLs. This implies that CFLs are viewed as an inferior technology and should not be considered as a close substitute for less efficient lightbulbs such as incandescents - an assumption implicitly embedded in much of the prior work on the "energy paradox". While the ability to sort and our normative appeals shift demand and increase willingness to pay, such effects are small and do little to reduce the amount of compensation that would be required to ensure adoption rates in excess of 25 percent.

We view our study as speaking to several branches of research. At the most applied level, it contributes to the literature on the adoption of energy efficient technologies and the "energy paradox". There is a long-standing belief amongst policymakers that investments in energy efficient technology offers a mutually beneficial prospect. For the investor, energy efficient technologies provide a way to save money on energy

\footnotetext{
${ }^{7}$ One possibility for the negative correlation is that indivdiuals alleviate feelings of guilt or the desire to purchase a CFL after opening the door and listening to our salesperson talk about energy efficiency.
} 
bills. For society, energy efficient technologies provide a way to reduce energy consumption and the negative externalities associated with such. Yet, many consumers seemingly leave money on the table by eschewing the purchase of such technologies; a phenomena called the energy paradox or energy efficiency gap Jaffe and Stavins (1995). Concerns for such investment inefficiencies has spurned a large empirical literature exploring potential causes of the energy efficiency gap and/or evaluating the effectiveness of policies to promote investment in energy saving technologies (for an overview of this work see, e.g., Gillingham et al., 2009; Allcott and Greenstone, 2012; Gillingham and Palmer, 2014; Gillingham et al., 2018; Gerarden et al., 2017). Our data not only show the low level of investment at baseline, but provide tools to enhance adoption.

In addition, we provide tools to measure impact of behaviorally motivated policies (such as the descriptive statements in which the decision to buy is triggered by way of peer effects). Our main contribution is to use structural methods to uncover the underlying distribution of households' willingness to pay and run policy counterfactual to estimate the degree of complementarity between social norms and prices in the identification of such distribution. In this respect, we find that social norms and prices are complements, rather than substitutes: while prices affect both the extensive and the intensive margin, social norms mostly affect the extensive margin only.

The paper also contributes to the growing literature that develops empirical methods to measure the impact of behaviorally motivated policies. In this manner, by using structural methods to uncover the underlying distribution of households' willingness to pay, and conducting policy counterfactuals to estimate the degree of complementarity between social norms and prices, we link closely to the literature that imposes structure on model and field experiment (see, e.g., DellaVigna et al., 2012, 2016b,a; Zhe Jin et al., 2010). Our study also serves as a complement to the literature on structural behavioral economics (Laibson et al., 2007; Conlin et al., 2007). We view this area as a ripe one for future studies to combine field experiments, behavioral economics, and formal models to address important economic and social issues.

The remainder of the paper is arranged as follows. Section 2 briefly summarizes some facts around household diffusion of technologies. Section 3 details our experimental methods and strategy for estimating the structural model. Section 4 presents descriptive statistics from the experiment and our reduced form results. Section 5 summarizes results from the structural model and policy simulations. Finally, Section 6 concludes, followed by the Appendices containing additional statistical evidence and a detailed account of our structural identification strategy. 


\section{Diffusion of Household Technologies}

Examining the technological adoption patterns across consumables amongst households represents an interesting glimpse of the nature and extent of diffusion. Figure 1 provides an ocular depiction of various adoption rates of new technologies over more than a century in the US. The figure reveals several interesting insights. First, while it is well known that technological progress has been fast paced in the last century, the figure shows that the rate at which newly commercialized technologies get adopted by consumers is also rapidly improving. For instance, the telephone was invented in 1876, but did not reach saturation until a century later, when landlines to households were adequate. Second, other modern era inventions such as microwaves, cell phones, smartphones, social media, and tablets each show fast adoption rates. Interestingly, the tablet computer went from 0 to 50 percent in roughly five years.

Figure 1: Technology adoption in U.S. households

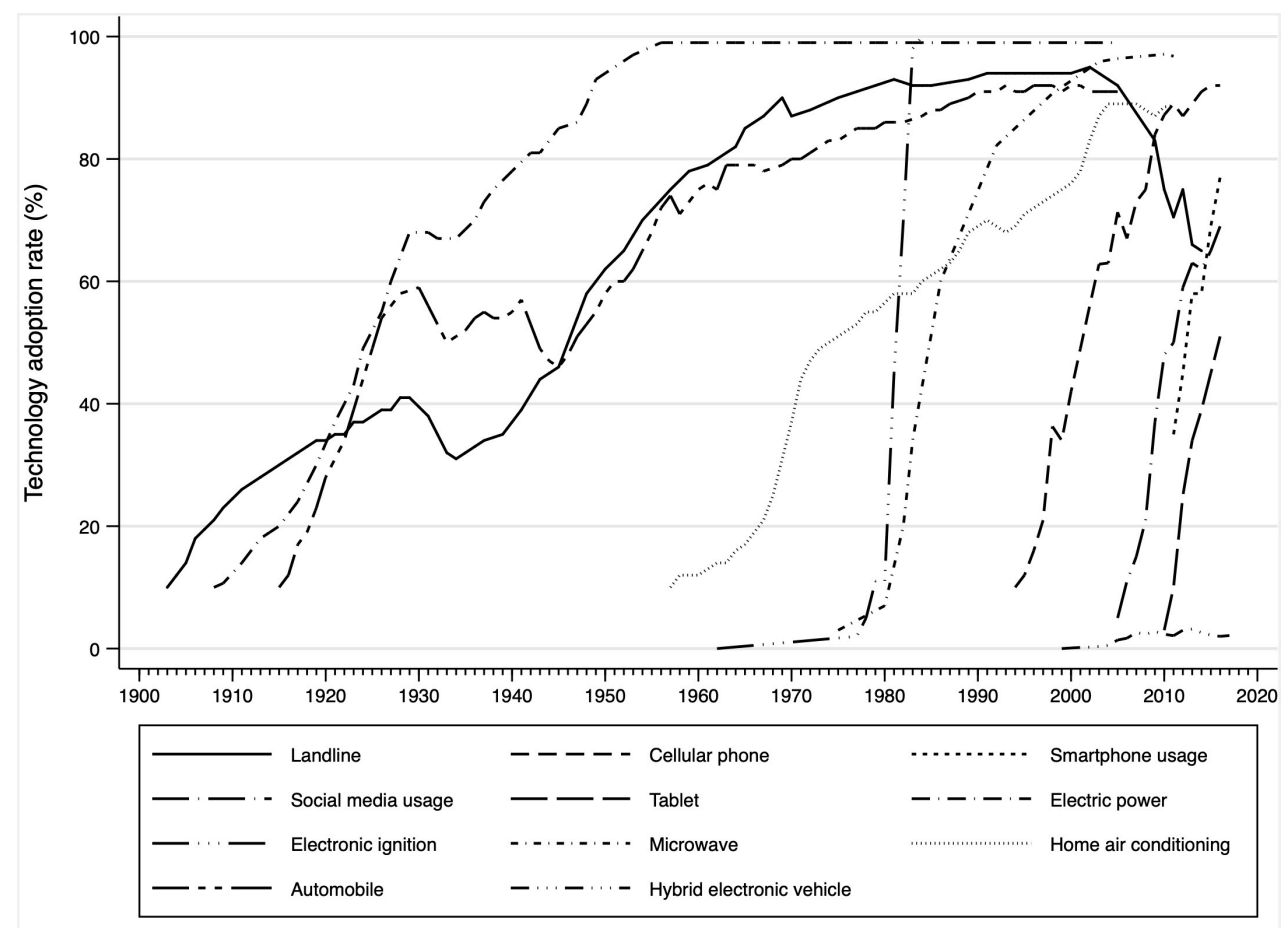

Note: Technology adoption rates, measured as the percentage of households in the U.S. using a particular technology. Adapted from Comin and Hobijn (2004) and from Alternative Fuels and Advanced Vehicles Data Center (US DoE).

One might ask, Why do newer technologies get adopted so quickly? It seems partly because modern tech needs less infrastructure in contrast with the inventions of years ago. Experts have also argued that the 
market has undergone a structural change, as consumers are "connected, fast-acting, and not afraid to adopt the new technologies that can quickly impact their lives for the better" (see Desjardins, 2018) Indeed, today new products can spread at speeds never seen before merely because of more rapid information diffusion.

A rich literature has developed in both the social sciences and the business and policy communities to help explain observed diffusion patterns. For example, the "Diffusion of Innovation Theory" is a social scientific construct developed by Roger (1962), and still serves to explain how an idea or product diffuses. The theory has been used to explain the tremendous amount variation that we observe in figure 1, as well as provide marketers a strategy to enhance product adoption.

Yet, while innovative goods are adopted at increasingly fast rates by households, there are some technologies that consumers are loathe to adopt and whose patterns of diffusion are markedly different than most other technologies. One such example is energy conserving technologies, even though consumers are seemingly becoming more environmentally conscious and demanding "green products". For example, as noted in Figure 1, while the diffusion of automobiles as a whole has followed a path similar to that for landline telephones and electric power, the diffusion of hybrid vehicles is markedly different (and lower) than that of other modern technologies such as cellular phones and tablets.

The marketing literature that has evolved in response to this emergence of green preferences is now deep and introduces new concepts such as green marketing and green consumerism (see Nath et al., 2013). Over the years various studies have explored factors that influence consumer adoption of sustainable products. In an effort to extend this line of work and more fully understand how to enhance the adoption patterns in figure 1, our paper combines pecuniary and non-pecuniary motives for technology adoption by households. In this way, we explore the effect of strategies suggested in the fields of economics and social psychology. We extend the literature on social norms and energy conservation by comparing social norms to prices in as close to an apples-to-apples comparison as possible utilizing a carefully designed field experiment.

Our focus on social norms is motivated by recent research suggesting that such messages are effective in encouraging energy conservation (see, e.g., Allcott, 2011; Ferraro and Price, 2013; Schultz et al., 2007). In each of these studies, households are provided information that compares how their energy (or water) use relates to that for other, similar households. Empirical results suggest that providing this type of information generates, on average, an approximate 2 to 3 percent decline in monthly usage. Amongst high consuming households, the observed declines are even more pronounced, ranging from 5.3 to 8.3 percent.

Research into motivating energy conservation has typically focused on curtailment rather than efficiency (Abrahamse et al., 2005). Yet, there is a recent literature that discusses efforts to promote energy efficient behavior and the adoption of CFLs more specifically. These efforts have not been designed as treatments to 
uncover the impact of various methods of encouragement but instead have typically considered CFL adoption policies and programs that had already occurred (Martinot and Borg, 1998; Lefèvre et al., 2006). The lack of experimental implementation in these studies resulted primarily in discussions of barriers to adoption for CFLs through survey results rather than providing information on methods to encourage adoption. The previous research has found that various barriers to CFL adoption exist, such as cost and quality as well as a lack of information and desire to change behavior, but has left many interesting questions unanswered (e.g. Lefèvre et al., 2006; Reynolds et al., 2007). Our paper differs from previous work on CFL adoption in that we utilize a carefully designed natural field experiment on technology adoption to estimate a structural model (see Harrison and List, 2004, for a general discussion of field experiments).

In this manner, our paper is methodologically connected to recent work exploring the welfare effects of nudges. When implementing interventions like ours, the fundamental question is whether they increase welfare: this includes both individual welfare (i.e. whether the individual is made better off by the intervention), but also societal welfare more broadly, which also includes the externalities imposed by excessive energy use. There is a recent literature on behavioral welfare economics that attempts to measure how different interventions affect welfare, taking seriously the insights from behavioral economics. In particular, the literature has focused mostly on internalities, which are consequences for an individual of her own actions, that she does not take into account (Herrnstein et al., 1993). Internalities are important because, if ignored when present, they can substantially change the results of empirical analysis (Baicker et al., 2015).

In the context of environmental economics, Allcott and Taubinsky (2015) study the welfare effects of two interventions that provided different types of information and/or prices about CFLs, using the "sufficient statistic" approach (introduced in the behavioral economics literature by Chetty, 2008), which identifies the marginal individual after taking internalities into account. ${ }^{8}$ Our approach is different from most of the literature in behavioral welfare economics in two aspects. First, we follow the door-to-door methodology of DellaVigna et al. (2012), by measuring welfare through the ability of individuals in our experiment to sort in or out of our treatments, what provides a complementary approach to the sufficient statistic approach. ${ }^{9}$ Second, we do not focus on internalities, but instead on the disutility from social pressure on taking actions that are environmentally conscious (Yoeli et al., 2013).

There is a related literature on behavior change that uses incentives as well as nudges (i.e., interventions that change the environment but do not restrict choice), in order to change behavior in a variety of contexts. These include, but are not limited to, exercise (Charness and Gneezy, 2009; Acland and Levy, 2016), smoking

\footnotetext{
${ }^{8}$ See also Chetty (2015) for a discussion of the sufficient statistic approach and its place in behavioral welfare economics.

${ }^{9}$ Other papers that apply the behavioral economics framework in the context of environmental/energy decisions are Allcott and Rogers (2014) and Allcott et al. (2014).
} 
cessation (Volpp et al., 2006, 2009; Giné et al., 2010) and water conservation (Ferraro et al., 2011; Ferraro and Price, 2013). Our focus on technology adoption instead of permanent behavioral change complements this work in that results of the actions we find are likely to be persistent provided reversing the adoption is difficult (Brandon et al., 2016). ${ }^{10}$

\section{Methods}

\subsection{Theoretical Underpinnings}

We streamline the stylized theoretical model that guided the design and implementation of our field experiment (details in Appendix B). We consider a 4-stage game between a potential customer (Anna) and a solicitor (Beppe).

1. In Stage 1, Anna may receive a flyer of Beppe's upcoming visit. She notices the flyer with probability $r \in(0,1]$ and, if the flyer has an Opt-Out box (Opt-Out treatment, see Section 3.2 below), she may decide to opt in (by not checking the box) with probability $\beta_{1} \in(0,1)$.

2. In Stage 2, Beppe visits the home. Anna answers the door with probability $h$. If she did not notice the flyer (or did not receive one), $h$ is equal to a baseline probability $h_{0} \in(0,1)$. If she noticed the flyer, she can adjust this probability to $\beta_{2} \in(0,1)$. In any case, if she does not answer, her payoff is normalized to zero.

3. In Stage 3, if Anna answers the door, she can buy at least one pack of CFLs (extensive margin) with probability $\beta_{3} \in(0,1)$.

4. In Stage 4, conditional on having purchased one pack already, she may also decide to buy an additional one (intensive margin) with probability $\beta_{4} \in(0,1)$.

In other words, Anna's timeline is broken down into four binary decisions, or stages, as shown in Figure 2. Figure 2 displays the sequential decision problem Anna is facing and identifies the three behavioral parameters governing her (binary) decisions. Specifically:

\footnotetext{
${ }^{10}$ The literature in behavioral welfare economics has recently emphasized the importance of focusing on general equilibrium effects (Handel, 2013; Spiegler, 2014; Jimenez-Gomez, 2019). We believe that general equilibrium are indeed of great importance, but we only focus on the partial equilibrium effect of our intervention, due to logistical constraints. The general equilibrium effects of our interventions are a priori ambiguous, partly because social norms (and therefore social pressure) depend on aggregate behavior, and it is difficult to make ex-ante predictions.
} 
Figure 2: Timeline of the structural model

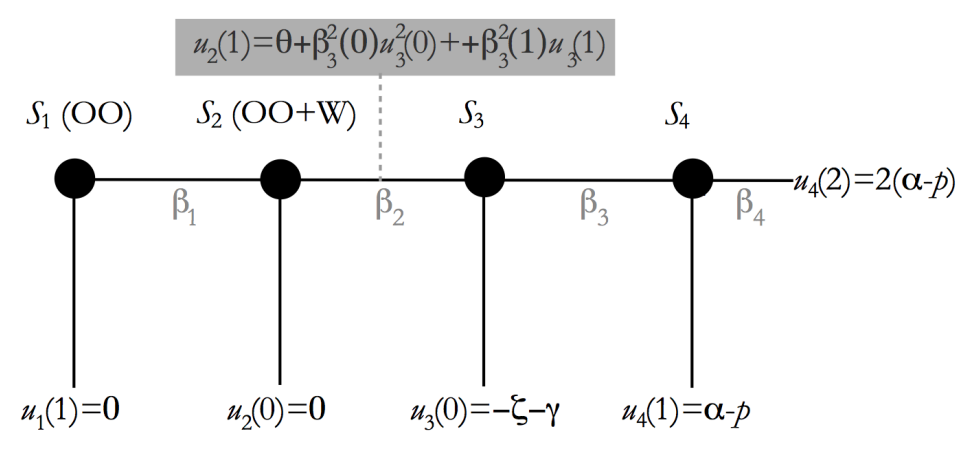

- Anna's value for a CFL pack, $\alpha$, accounts for financial considerations (i.e., a reduction in energy costs) as well as for pure and impure altruism (warm glow). Since the experiment is not designed to identify these components, we use a specification that is general enough to encompass all.

- Anna's sensitivity to social pressure, $\varsigma$, is positive when Anna feels bad about not buying anything facing Beppe in a face-to-face interaction (i.e., after answering the door). In this respect, this parameter is very similar to that being used by DLM.

- Anna's curiosity, $\theta$, is positive when Anna is interested to learn more about energy saving solutions independently on her willingness to buy (see the extensive discussion in Section 3.2).

In Appendix B we solve the model "backwards", starting from Stage 4, under the assumption Anna is aware of her own parameter preferences at the time the latter are relevant for choice (i.e., $\alpha$ in Stage 4 , $\varsigma$ in Stage 3 and $\theta$ in Stage 2) and rationally anticipates her response conditional on her information state at each stage. Figure 3 summarizes the main features of the solution of our model as far as the extensive (Stage 3) and intensive (Stage 4) margins are concerned.

Denote by $\alpha^{*}=p$ the threshold for $\alpha$ which identifies the (intensive) marginal buyer in Stage 4 . Given our linearity assumption, Anna will buy an additional pack whenever $\alpha>\alpha^{*}=p$. Therefore, the belief associated to this intensive margin, at all prior stages $h<4$ will then be $\beta_{4}^{h}=1-\Psi\left(\alpha^{*}\right)$, where $\Psi(\cdot)$ denotes the cumulative (normal, in the structural estimations of Section 5) density that defines our heterogenous population. By the same token, in Stage 3, Anna decides whether to buy some pack or nothing (extensive margin) if $\varsigma$ is sufficiently high. In Appendix B we identify the extensive marginal buyer as a function of the parameters $\alpha$ and $\varsigma$. Figure 3 illustrates the case of the (i.i.d.) normal distributions of $\alpha$ and $\varsigma$ as in Model 1 in our structural estimations (see Section 5). As Figure 3 shows, $\alpha^{*}$ corresponds to the ruling price, $p$, while $\varsigma^{*}(\alpha)$ is decreasing in $\alpha$. This is because a higher value of $\alpha$ (i.e., higher evaluation for the CFL) lowers 
Figure 3: Testable hypotheses

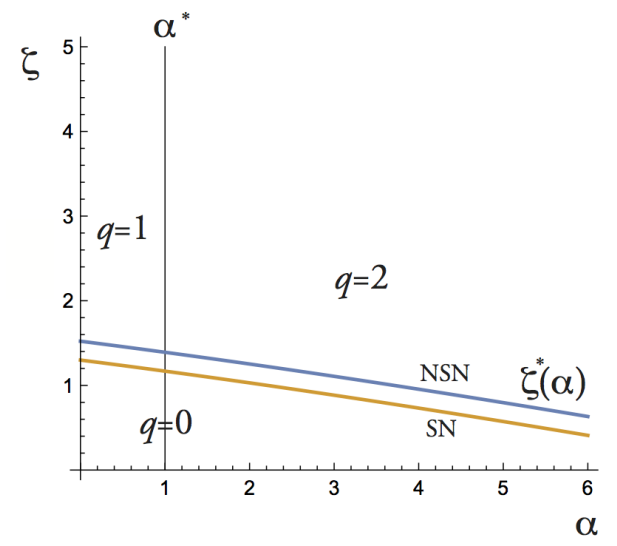

a) $p=1$

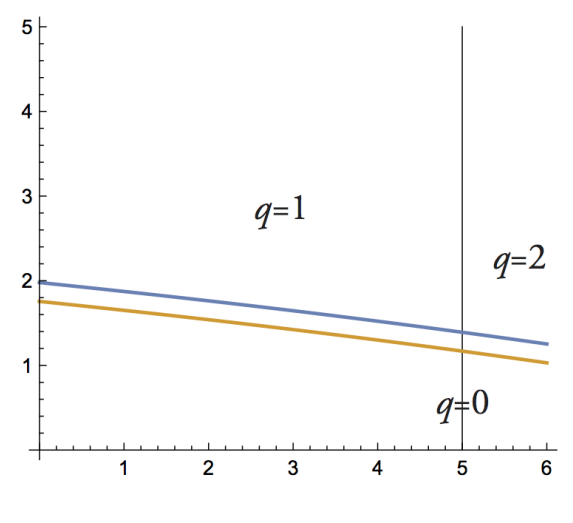

a) $p=5$

Note: Figure 3 indicates the different regions for buying, no buying $[q=0]$, extensive margin $[0<q<2]$ and intensive margin $[q=2]$. The regions are a function of the value parameter, $\alpha$, and the social pressure parameter, $\varsigma$.

the impact of social pressure on the marginal adopter. Also notice that a positive social norm facilitates adoption by shifting down the extensive margin threshold.

While Figure 3 is calibrated according with the structural estimation of Section 5, in Appendix B we prove that the qualitative features of our model are preserved under very mild distributional restrictions.

\subsection{Field Experimental Design and Implementation}

Our field experiment was implemented by offering households up to 2 packages of CFLs to purchase in a doorto-door design (each package contained 4 CFLs). Approaching consumers at their doors may not appear to be the most applicable method for technology adoption. However, energy conservation programs often employ door-to-door approaches to encourage adoption of technologies such as CFLs. Examples of recent programs are the Clean Development Mechanism projects in the South Urban Lahore district of Pakistan and Visakhaptanam India, and a door-to-door energy conservation campaign distributing environmental technologies in Boulder, Colorado in the summer of 2010. Although there is a natural interest in working within stores, that setting would provide a select sample of consumers. While such a select sample is of interest, the benefits gained by installing CFLs is immediate and thus an ideal sample to approach is all consumers who use traditional incandescent light bulbs. Further, approaching households directly allows for greater ease of allowing sorting of households, which is necessary to identify pieces of our structural model.

In total, there are 18 treatment cells in the experimental design. Table 1 provides the sample size by 
Table 1: Treatment Sample Size

\begin{tabular}{ccccc}
\hline \hline Price per Pack & Social Norm & No Warning & Warning & Opt-Out \\
\hline \multirow{3}{*}{$\$ 1$} & No & 480 & 474 & 473 \\
& Low & 447 & 508 & 535 \\
& High & 454 & 469 & 481 \\
\hline \multirow{3}{*}{$\$ 5$} & No & 435 & 546 & 501 \\
& Low & 493 & 544 & 491 \\
& High & 431 & 511 & 542 \\
\hline Total & & 2740 & 3052 & 3023 \\
\hline \hline
\end{tabular}

Each cell gives the number of households approached for each treatment group.

treatment cell. Households were approached during the day on weekends by University of Chicago students employed through the Becker Center at the University of Chicago. Students were hired upon responding to job advertisements placed around the campus of the University of Chicago and on the University's main electronic help wanted web site (marketplace.uchicago.edu). After responding to the advertisement, students were briefly interviewed. Every student who completed the interview was hired and given a time to come back for a training session. Each training session lasted approximately 30 minutes and were conducted with multiple students so that they could practice scripts with each other.

Students were driven to the suburbs on Saturdays and Sundays to approach households over 4 one-hour blocks of time: 10 a.m. to 11 a.m., 11 a.m. to noon, 1 p.m. to 2 p.m. and 2 p.m. to 3 p.m. Households were grouped into blocks containing roughly 25 houses. Each block of houses was randomly assigned to a treatment so that a given student typically had a different treatment each hour. The CFL sales took place on weekends between June 2009 and June 2010 with a break in the winter months and on weekend days when it was either too cold or raining.

Households in the following locations around Chicago were approached: Arlington Heights, Elmwood Park, Evanston, Lemont, Libertyville, Oak Park, River Forest, Roselle, Skokie, and Wheaton. These suburbs range in median household income from $\$ 47,315$ to $\$ 89,284$ as reported in the 2000 U.S. Census (1999 dollars). This is in comparison to the United States national and Illinois median household incomes for the same period - \$41,994 and $\$ 46,590$ respectively. The sample approached in our study had higher median incomes then is typical in the U.S. This suggests an important caveat to our results and may limit the generalizability of our findings.

Our theoretical model suggests two treatments to parse the impacts of the valuation for CFLs (private and altruistic) vs. social pressure, allowing consumers to select into or out of interacting with a salesperson. In order to provide households this opportunity, a team of researchers and interns placed flyers on households in 
the Warning and Opt-Out treatments the day prior to the students visiting households. These flyers, shown in 4 , informed the household that it would be visited the following day by someone with an "offer for purchase and discuss energy saving light bulb options". While placing the flyers on doors, the researchers and interns only interacted with members of the households if they were approached directly (i.e. household members were outside in the yard and witnessed the placement of the flyer). Although the student salespersons were aware of the different scripts and prices for each treatment, they were not aware that only some houses had been warned of the visit the day prior via the flyers. This ensures that the proportion of households that we warn that see the warning have an ability to adjust the likelihood of being home and answering the door, compared with the No Warning treatment, in which no flyer is delivered. ${ }^{11}$

To provide a setting consistent with our environment, we introduce a novel parameter that we call curiosity. This parameter measures the individual's expectation about her utility gain from the interaction with the solicitor, independent of any price, social norm and purchasing decision. In other words, it measures the expectation of the gain from the interaction itself, which is precisely what we understand by curiosity. Note that this parameter is not present in DLM since in that case the flyers contained information relevant to the treatments (price, social pressure). In our design the flyers contain minimal information. While this approach is customary in real-world interventions that target energy efficiency, it is by design impossible to have a measure of households sorting behavior based on the information that is absent from the flyer (prices and social norms), although they are still able to sort due to their curiosity.

Scientifically, the motivation to include a curiosity parameter in estimation arises from a growing series of psychological studies where curiosity has been defined as the desire to know. (i.e. Litman et al., 2005). ${ }^{12}$ In particular, Loewenstein (1994) highlights that curiosity can be characterized as a loss-aversion phenomenon, that is a situation in which the opportunity to loss information is considered to be worse than a situation in which one merely does not acquire the same information (i.e. Alós-Ferrer et al., 2018). This phenomenon is related to the interest in learning something new (Charness et al., 2003). Hence, the curiosity effect may be generalized to all goods that have an element of uncertainty associated with them, since curiosity arises from a perception gap in knowledge. Indeed, curiosity might motive consumers to purchase a desirable new product (see among others, Bernard et al., 2005; Loewenstein, 2000); alternatively, curiosity may play a role in setting expectations in prices, causing the endowment effect (Van De Ven et al., 2005).

\footnotetext{
${ }^{11}$ Social norm and price treatments provide variation to identify the impact of social pressure and price on the decision to purchase. However, the decision to purchase could be due to underlying social pressure present in all treatments vs. the private and public attributes of the purchase. Moreover, we are unable to identify the public vs. private valuation for CFLs, so we will consider the individual valuation for CFLs that combines the two.

${ }^{12}$ These studies analyze two categories of epistemic curiosity: the interest-type curiosity and the deprivation-type curiosity. The first involves the anticipated pleasure of new discoveries and the second reduces uncertainty of knowledge gaps.
} 
Figure 4: Door-hanger examples

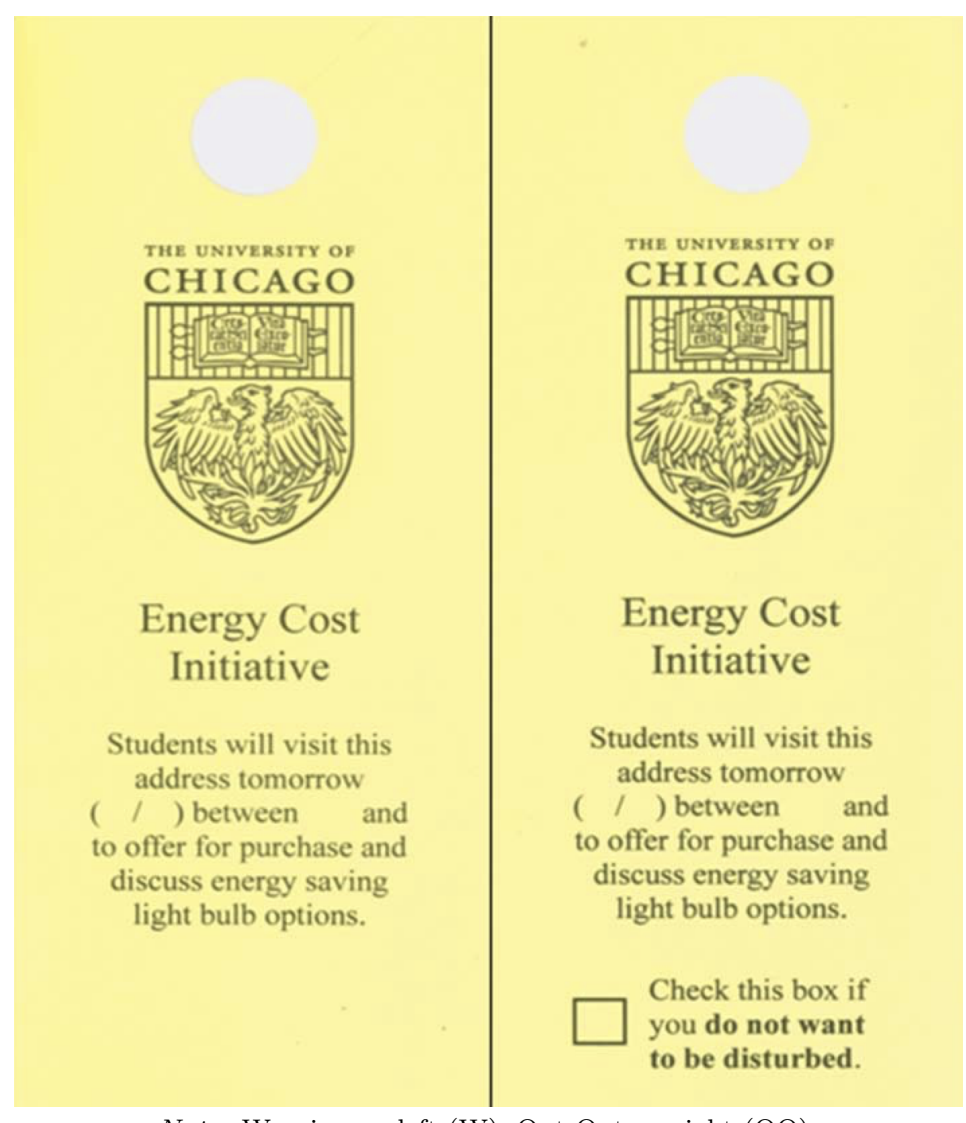

Note: Warning on left (W), Opt-Out on right (OO).

The main treatments were delivered through scripts given to student salespersons for each one-hour treatment block of households. The scripts varied in two ways: stated social norm and sale price of CFL package. The CFLs sold door-to-door were priced between $\$ 3.85$ and $\$ 7.15$ for a package of 4 CFLs in stores throughout the Chicago area. The price tended to be around $\$ 5.00$ when tax was included so we set our baseline price for a package of 4 CFLs at $\$ 5.00$. We included one other price point, a low price of $\$ 1.00$. The low price of $\$ 1.00$ was chosen for a number of reasons. The main reason is that, depending on quality and type, a package of 4 incandescent light bulbs can range from $\$ 0.33$ to $\$ 5.00$ but is typically around $\$ 1.00$. Thus, pricing the package of 4 CFLs at $\$ 1.00$ made it reasonably equivalent to purchasing a new package of incandescent light bulbs. A secondary reason was that logistically, selling goods for $\$ 5.00$ and $\$ 1.00$ simplifies providing change for purchases.

Social pressure can be applied in a number of ways to varying degrees of efficacy. For example, psychol- 
ogists have written extensively on approaches specific to door-to-door sales such as the "Foot-in-the-Door" approach and the "Door-in-the-Face" approach. As discussed in the literature review (see Section 2), recent research has found social norms to be an effective social psychological pathway to impact a person's decisions. This led us to incorporate social norms into our experimental design as a test for the impact that social-psychology can have on adoption. In order to incorporate social norms, a script without a statement of social norms, referred to as the "Neutral Frame" treatment, and two treatments involving a statement of social norms, "Social Norm Low" and "Social Norm High" were run (hereafter N, L, H, respectively). Both social norm treatments augment the general Neutral Frame script by one statement prior to stating the price. Social Norm Low uses the phrase: "For instance, did you know that 70\% of U.S. households own at least one CFL?" while the Social Norm High treatment uses the phrase: "For instance, did you know that $\mathbf{7 0 \%}$ of the households that we surveyed in this area own at least one CFL?" The change in the proximity with which the social norm is stated follows in line with Goldstein et al. (2008).

In addition, including variation in social pressure and price allows for a pricing of social pressure as will be discussed in the results. Further, analyzing not only the decision to purchase but considering also how many packages of CFLs were purchased permits some indication of whether consumers appear to be "buying out" of social pressure or "buying in" to a new technology due to information contained in the social norm.

\section{Descriptive statistics and reduced-form results}

Given the multi-stage structure of our field experiment, our reduced form analysis is built around a multivariate linear probability model, where we estimate the joint probability of our three binary actions (opening the door and choosing along the extensive/intensive margin) using different covariates depending on the information sets of each stage. This model is built on the classical linear probability model with normally distributed errors, and combines naturally into a system of equations (Roodman, 2011). Parameters are consistently estimated in two steps: $i$ ) a set of equation-by-equation linear estimations and $i i$ ) a set of simultaneous estimations that treats them as related to each other. ${ }^{13}$ In other words, the results of the simultaneous estimation maximizes a likelihood function that includes all three equations in order to take into account the full covariance structure of three decisions and the interdependence across choices (the equations are not independent since they are computed on a gradually reducing subject pool).

The general specification for our three-equations model is:

\footnotetext{
${ }^{13}$ The equation-by-equation estimation fit individual models as starting point for full model fit.
} 


$$
y_{i j m}^{*}=\beta_{n} X_{i j m}+\eta_{j}+\lambda_{k}+\varepsilon_{j m}
$$

where

$$
y_{i j m}=f\left(y_{i j m}^{*}\right)= \begin{cases}0 & \text { if } y_{i j m}^{*} \leq 0 \\ 1 & \text { if } y_{i j m}^{*}>0\end{cases}
$$

where $y_{i j, m}^{*}$ capture the choice at stage $m=1,2,3$ for household $i$ located in suburb $j$, where $\beta_{n}$ is a vector of coefficients, $X_{i j m}$ is a vector of observed variables that influence the choice of individuals, that are different across equations:

- $M_{1}$ : Choice to open the door depends on the warning level $(W, O O)$;

- $M_{2}$ : Choice to purchase at least 1 pack of CFLs depends on the warning treatments, the social norms $(L, H)$, and the high price $(\$ 5) ;{ }^{14}$

- $M_{3}$ : Choice to purchase at least 2 pack of CFLs depends on the social norms $(L, H)$ and the high price $(\$ 5)$;

We include the vectors $\eta$ and $\lambda$ that represent respectively, salesperson and suburbs specific dummies and we clustered robust standard errors at date-solicitor time blocks level in order to control for possible randomization fixed effects. Finally, $\varepsilon$ is the error term specific to the equation of the $m$-th behavior. We estimate the model using maximum likelihood (ML) estimation, assuming that the errors are normally distributed.

The number of observations varies by task given the sequential structure of the experiment (see Figure 2). As such, each equation is conditioned on a reduced data sample: 8815 (2848) [290] observations in stages 1 (2) [3], respectively. ${ }^{15}$ But, importantly, the three equations take into account i) the impact of the different warning level, ii) the rate of purchase of at least one pack of CFLs and iii) the rate of purchase of second pack of CFLs.

Table 2 reports summary statistics of the distributions of the various outcomes of interest. The first column in table 2 shows the descriptive statistics for the Opt-Out treatment, which is the fourth stage in our structural model. This result concerns the possibility of sorting out by checking the appropriate box in the flyer (conditional on seeing the flyer). Columns 2-4 contain summary statistics on probability of answering the door and probability of purchasing one or two packages.

\footnotetext{
${ }^{14}$ In the second equation we use the warning variable to collect information for warning as well as opt-out treatments.

${ }^{15}$ We use the cmp Stata command for practical implementation (Roodman (2009)) that is built on a maximum - likelihood estimator. We believe that this technique is the most appropriate to address simultaneously the three equations related to three stages structure of the model.
} 
Table 2: Summary Statistics

\begin{tabular}{cccccc}
\hline \hline & Opted Out & Open Door & Buy & Buy|Open & $\mathrm{Q}=2 \mid$ Buy \\
\hline No Warning & & 0.367 & 0.0321 & 0.087 & 0.443 \\
& & $(0.482)$ & $(0.176)$ & $(0.283)$ & $(0.500)$ \\
Obs. & 2740 & 2740 & 1006 & 88 \\
\hline Warning & & 0.332 & 0.038 & 0.115 & 0.564 \\
& & $(0.471)$ & $(0.192)$ & $(0.320)$ & $(0.498)$ \\
Obs. & 3052 & 3052 & 1014 & 117 \\
\hline Opt-Out & 0.116 & 0.274 & 0.028 & 0.103 & 0.529 \\
& $(0.321)$ & $(0.446)$ & $(0.165)$ & $(0.307)$ & $(0.502)$ \\
Obs. & 3023 & 3023 & 3023 & 828 & 85 \\
\hline Total & 0.116 & 0.323 & 0.033 & 0.102 & 0.517 \\
& $(0.321)$ & $(0.468)$ & $(0.178)$ & $(0.302)$ & $(0.500)$ \\
Obs. & 3023 & 8815 & 8815 & 2848 & 290 \\
\hline \hline
\end{tabular}

Note: Figures in table are means and standard deviations (in parentheses). For example, "Opted Out" is calculated as $0.116=352$ households checking the box divided by 3023 total households. In the remaining figures for this treatment the 352 households of the 3023 are included as doors knocked on but not answered.

Table 3 complements table 2 by showing the first set of conditional results related to the equation-byequation estimations. Table 4 provides a second complement to the raw data by summarizing empirical estimates from the second set of simultaneous estimation.

Table 3: Equation-by-equation linear estimations

\begin{tabular}{|c|c|c|c|c|}
\hline & Open Door & Buy & Open & $\mathrm{Q}=2 \mid \mathrm{Buy}$ \\
\hline Warning & $\begin{array}{c}-0.026^{* *} \\
(0.013)\end{array}$ & & & \\
\hline Opt-Out & $\begin{array}{c}-0.077^{* * *} \\
(0.013)\end{array}$ & & & \\
\hline Warning treatments & & $\begin{array}{r}0.03 \\
(0 .\end{array}$ & $\begin{array}{l}3 * * * \\
012)\end{array}$ & \\
\hline Social Norm Low & & $\begin{array}{l}0 . \\
(0 .\end{array}$ & $\begin{array}{l}003 \\
017)\end{array}$ & $\begin{array}{l}-0.053 \\
(0.094)\end{array}$ \\
\hline Social Norm High & & $\begin{array}{r}0.03 \\
(0 .\end{array}$ & $\begin{array}{l}5 * * * \\
014)\end{array}$ & $\begin{array}{l}-0.060 \\
(0.081)\end{array}$ \\
\hline Price $\$ 5$ & & $\begin{array}{r}-0.0 \\
(0 .\end{array}$ & $\begin{array}{l}54 * * * \\
011)\end{array}$ & $\begin{array}{c}-0.319^{* * *} \\
(0.066)\end{array}$ \\
\hline Solicitors FE & YES & & $\mathrm{ES}$ & YES \\
\hline Suburbs FE & YES & & $\mathrm{ES}$ & YES \\
\hline Constant & $\begin{array}{c}0.351^{* * *} \\
(0.024)\end{array}$ & $\begin{array}{c}0.09 \\
(0 .\end{array}$ & $\begin{array}{l}0 * * * \\
030)\end{array}$ & $\begin{array}{c}0.510^{* * *} \\
(0.168)\end{array}$ \\
\hline Obs. & 8815 & & 248 & 290 \\
\hline
\end{tabular}

Note: All regressions include solicitors and suburbs fixed effects. Standard errors (in parentheses) are clustered at date-solicitor blocks level. 
Table 4: Simultaneous estimations

\begin{tabular}{lccc}
\hline \hline & Open Door & Buy $\mid$ Open & $\mathrm{Q}=2 \mid$ Buy \\
\hline Warning & $-0.026^{*}$ & & \\
& $(0.015)$ & & \\
Opt-Out & $-0.077^{* * *}$ & & \\
& $(0.015)$ & & \\
Warning treatments & & $0.062^{* *}$ & \\
& & $(0.026)$ & \\
Social Norm Low & & 0.005 & -0.063 \\
& & $(0.018)$ & $(0.084)$ \\
Social Norm High & & $0.038^{* * *}$ & -0.094 \\
& & $(0.014)$ & $(0.093)$ \\
Price $\$ 5$ & & $-0.085^{* * *}$ & $-0.300^{*}$ \\
& & $(0.012)$ & $(0.158)$ \\
Solicitor effects & YES & YES & YES \\
City effects & YES & YES & YES \\
Constant & $0.351^{* * *}$ & $0.463^{*}$ & -0.632 \\
& $(0.031)$ & $(0.242)$ & $(1.693)$ \\
\hline Obs. & 8815 & 8815 & 8815 \\
\hline \hline$* p<.1 ; * * p<.05 ; * * * p<.01$ & &
\end{tabular}

Note: All regressions include solicitors and suburbs fixed effects. Standard errors (in parentheses) are clustered at date-solicitor blocks level.

Together, these three tables lead to several results highlighting the households' decisions stage by stage:

\section{Result I: Our treatments induce differential sorting.}

Concerning the Opt-out treatment, in table 2 we find that approximately 11.6 percent of all households check the Opt-Out box, and 27.4 percent of subjects in that treatment answer the door. Table 2 also shows that people in the Warning and Opt-Out treatments are much less likely to answer the door: 9.5 and 25.3 percent less likely than their counterparts in the NW group. These raw statistics highlight that households warned in advance of a visit by a salesperson attempt to avoid the interaction, using the Opt-Out option when available, suggesting that there might be scope for interesting welfare implications and heterogeneities, as we discuss in Section 5.

The conditional analyses further support Result I. For example, column 1 of Table 4 reports the estimated coefficients of households who choose to answer the door in our warning treatments (W and OO). Households in Warning and Opt-out treatments are 2.6 and 7.7 percentage points less likely to answer the door than their counterparts approached without warning. Interestingly, an identical result is found in table 3 . Taken together, results in the three tables reveal the differential sorting that our treatments induced, and are suggestive of social pressure being an important driver of observed behavior. Furthermore they are consistent with the assumption that checking the Opt-Out box lowers the costs of avoiding the salesperson. In this way, 
the Opt-out increases sorting. As we lower the cost of avoiding such interactions (such as in the Opt-Out treatment), we observe further reductions in the rate of door answering.

A second and third result follows from exploring the purchase decision more deeply.

\section{Result II: Social norms affect consumers on the extensive margin.}

\section{Result III: Prices affect both the intensive and extensive margins.}

Tables 3-5 provide empirical support for Results II and III. Table 5 reports a data summary about purchase decisions across the three psychological frames: i) Neutral frame, ii) Low social norm, and iii) High social norm and for the two price levels: $\$ 1$ and $\$ 5$, respectively. Whereas 2.7 percent of all households approached in our Neutral treatment ultimately purchase at least one package of CFLs, purchase rates in our Low norm treatment are approximately 18.5 percent higher. Increasing the proximity between the household and comparison group, as in the High norm treatment, leads to even further increases in purchase rates: people in this treatment are 44.4 percent more likely than counterparts in the Neutral group to purchase CFLs. We observe similar differences if we focus on purchase rates conditioned on answering the door. For example, the results in table 5 show that households that answer the door in our High (Low) social norm treatment are approximately 45.6 percent (41.7 percent) more likely to purchase CFLs than their counterparts in the neutral treatment. These differences suggest the importance of proximity when using social norms, and are consonant with previous research (Goldstein et al., 2008).

Table 5: Treatment Effects on the Purchase Decision

\begin{tabular}{|c|c|c|c|c|c|c|c|c|c|}
\hline \multirow[b]{2}{*}{ Social norm } & \multicolumn{3}{|c|}{ Buy } & \multicolumn{3}{|c|}{ Buy | Open } & \multicolumn{3}{|c|}{$\mathrm{Q}=2 \mid$ Buy } \\
\hline & $p=1$ & $p=5$ & Total & $p=1$ & $p=5$ & Total & $p=1$ & $p=5$ & Total \\
\hline Neutral Frame & $\begin{array}{c}0.040 \\
(0.196) \\
1427\end{array}$ & $\begin{array}{c}0.015 \\
(0.121) \\
1482\end{array}$ & $\begin{array}{c}0.027 \\
(0.163) \\
2909\end{array}$ & $\begin{array}{c}0.110 \\
(0.313) \\
520\end{array}$ & $\begin{array}{c}0.046 \\
(0.210) \\
475\end{array}$ & $\begin{array}{c}0.079 \\
0.270 \\
995\end{array}$ & $\begin{array}{c}0.631 \\
(0.487) \\
57\end{array}$ & $\begin{array}{c}0.182 \\
(0.395) \\
22\end{array}$ & $\begin{array}{c}0.506 \\
(0.503) \\
79\end{array}$ \\
\hline $\begin{array}{l}\text { Social Norm Low } \\
\text { Obs. }\end{array}$ & $\begin{array}{c}0.048 \\
(0.215) \\
1490\end{array}$ & $\begin{array}{c}0.016 \\
(0.127) \\
1528\end{array}$ & $\begin{array}{c}0.032 \\
(0.176) \\
3018\end{array}$ & $\begin{array}{c}0.174 \\
(0.379) \\
414\end{array}$ & $\begin{array}{c}0.055 \\
(0.230) \\
451\end{array}$ & $\begin{array}{c}0.112 \\
(0.316) \\
865\end{array}$ & $\begin{array}{c}0.667 \\
(0.475) \\
72\end{array}$ & $\begin{array}{c}0.320 \\
(0.476) \\
25\end{array}$ & $\begin{array}{c}0.577 \\
(0.496) \\
97\end{array}$ \\
\hline $\begin{array}{l}\text { Social Norm High } \\
\text { Obs. }\end{array}$ & $\begin{array}{c}0.055 \\
(0.230) \\
1404\end{array}$ & $\begin{array}{c}0.024 \\
(0.154) \\
1484\end{array}$ & $\begin{array}{c}0.039 \\
(0.195) \\
2888\end{array}$ & $\begin{array}{c}0.158 \\
(0.366) \\
492\end{array}$ & $\begin{array}{c}0.073 \\
(0.260) \\
496\end{array}$ & $\begin{array}{c}0.115 \\
(0.320) \\
988\end{array}$ & $\begin{array}{c}0.538 \\
(0.502) \\
78\end{array}$ & $\begin{array}{c}0.333 \\
(0.478) \\
36\end{array}$ & $\begin{array}{c}0.474 \\
(0.501) \\
114\end{array}$ \\
\hline $\begin{array}{l}\text { Total } \\
\text { Obs. }\end{array}$ & $\begin{array}{c}0.0480 \\
(0.214) \\
4321\end{array}$ & $\begin{array}{c}0.018 \\
(0.135) \\
4494\end{array}$ & $\begin{array}{c}0.033 \\
(0.178) \\
8815\end{array}$ & $\begin{array}{c}0.145 \\
(0.352) \\
1426\end{array}$ & $\begin{array}{c}0.058 \\
(0.234) \\
1422\end{array}$ & $\begin{array}{c}0.102 \\
(0.302) \\
2848\end{array}$ & $\begin{array}{c}0.609 \\
(0.489) \\
207\end{array}$ & $\begin{array}{c}0.289 \\
(0.456) \\
83\end{array}$ & $\begin{array}{c}0.517 \\
(0.501) \\
290\end{array}$ \\
\hline
\end{tabular}

Note: Figures in table are means and standard deviations (in parentheses). For example, column 1 "Buy" is calculated as $0.04=57$ households buying at least a pack of CFLs divided by 1427 total households approached in Neutral treatment with price $=1 \$$. Column 2 "Buy | Open" is calculated as $0.11=57$ households buying at least a pack of CFLs divided by 520 total households who open the door when approached in Neutral treatment with price $=1 \$$. Column 3 "Q=2| Buy" represents households that choose to buy two packs of CFLs. 
There are several further bits of empirical support for Results II and III. First, summary results in table 5 indicate that an increase in price from $\$ 1$ to $\$ 5$ generates a significant decrease in the fraction of people purchasing at least one package: in many cases by large percentages. These results highlight that the demand curve for CFLs is indeed downward sloping in general. When we restrict the analysis to the households that purchased 2 packs of CFLs (rightmost panel in table 5), we find a significant role for prices.

Second, turning to tables 3 and 4 we find complementary evidence. For example, in column 2 of table 3 we find that both prices and social norms affect the probability of purchase. Yet, in column 3 of table 3 we find that while price affects the probability of purchasing a second package, social norms play no statistically significant role. Likewise, in column 2 of table 4 , we find that when we conduct a simultaneous equation estimation we find that both price and social norms matter for the purchases decision. Yet, in column 3 of table 4, when modeling purchasing two packages only price is significant. As a whole, in terms of economic significance, tables 3-5 paint a consonant picture: the high norm increases the probability of purchase by roughly 40 percent compared to the control and decreasing the price from five dollars to one dollar increases the probability of purchase by roughly three-fold. Viewed in their totality, these reduced form results suggest an important complementarity between pecuniary and non-pecuniary factors on the diffusion of new technologies.

\section{Result IV: the correlation across choices.}

Finally, table 6 reports the $\rho$ terms associated to the cross-equation correlation matrix between the choices. ${ }^{16}$

Table 6: Correlation matrix ( $\rho$ terms)

\begin{tabular}{lccc}
\hline \hline & Open Door & Buy $\mid$ Open & $\mathrm{Q}=2 \mid$ Buy \\
\hline Open Door & 1 & $-0.832^{*}$ & $1.600^{* * *}$ \\
& & $(0.442)$ & $(0.512)$ \\
Buy | Open & 1 & -0.856 \\
$\mathrm{Q}=2 \mid$ Buy & & $(0.603)$ \\
\hline \hline$* p<.1 ; * * p<.05 ; * * * p<.01$ & 1 \\
\hline \hline
\end{tabular}

Addressing simultaneously empirical estimations we find evidence of opening the door and choosing along the extensive/intensive margin. Indeed, the two equations related to the decisions to open the door and the decisions to purchase at least 1 or 2 packages of CFLs are strongly correlated $\left(\rho_{12}=-0.832\right.$ and $\rho_{13}=1.600$, respectively). Looking to the not statistically significant correlation between the error terms of the second and third equation $\left(\rho_{23}=-0.856\right)$ we could assume that households which register a higher likelihood of purchase at least 1 pack of CFLs are also less likely to purchase the second package this suggests that the

\footnotetext{
${ }^{16} \rho_{12}=-0.832^{* *}, \rho_{13}=1.600^{* * *}$ and $\rho_{23}=-0.856 . \rho$ is the standard error for the correlation coefficient between the three error terms. Basically, $\rho$ is just the correlation between the residuals of the three equations.
} 
choices are almost independent - perhaps reflecting that our treatments attract different types for whom the underlying motivation for purchasing the first package of CFLs differ.

In Appendix A we report as robustness check the traditional approach that shows the estimated coefficients of ten linear probability models analogous to the regression in Equation 1, that do not consider the intrinsic correlation between choices. ${ }^{17}$ Table A1 shows results for the sample of 8815 households unconditional on whether or not they answer the door, table A2, shows findings for the subsample of 2848 households who answered the door, and table A3 shows results for the subsample of 290 households who purchased at least 1 pack of CFLs. Results from these models provide insights consistent with those from our main specifications - norms and prices impact behavior along different margins. Norms only impact the extensive margin decision whereas prices impact choice along both the extensive and intensive margins.

\section{Structural estimation}

We view the reduced form results as providing interesting insights on their own, yet we can complement those by imposing further structure on the estimation. Identification of theoretical parameters through structural estimation permits a discussion of the policy and welfare impacts of a door-to-door campaign to encourage energy conservation technologies, and the impact of using social-psychology statements. Because our natural field experimental design was informed by the theory, a thorough discussion concerning the welfare impacts of the various policy instruments employed (i.e., subsidy incentives, social pressure, and warning levels) from purchasing CFLs is possible. The parameters of the structural model are estimated using Maximum Likelihood (ML), and we summarize the structural estimates in three sub-sections.

\section{I: Estimated Parameters}

Empirical results from the structural estimations are reported in Table 7, which reports the estimated parameters of three alternative specifications. Informed by the reduced form results of Section 4, Model (1) does not condition the estimate of $\mu_{\alpha}$ on social norms. In other words, Model (1) restricts social norms to have an impact on the extensive margin only while allowing prices to impact decisions along both the extensive and intensive margins. Model (2) relaxes this restriction by allowing social norms to influence the

\footnotetext{
${ }^{17}$ We report the estimated coefficients of ten linear probabilities models of the form: $y_{i j k}=Z_{i j k} \delta+\eta_{j}+\lambda_{k}+\varepsilon_{i j}$, where $y_{i j k}$ equals 1 if household $i$ located in suburb $j$ opened the door to salesperson $k$, and 0 otherwise. The vector $\mathrm{Z}$ includes indicators for: i) W and OO treatments (columns 1 and 2), ii) L and $\mathrm{H}$ treatments (columns 3 and 4), iii) high price (columns 5 and $6), i v$ ) all treatments (columns 7 and 8) and $v$ ) all treatments and interaction terms between high price and $\mathrm{L}$ and $\mathrm{H}$ pressure level (columns 9 and 10), while the vector $\eta$ includes salesperson specific dummy variables and the vector $\lambda$ suburbs-specific dummies. Moreover, clustered robust standard errors are included at date-solicitor time blocks level in order to control for possible randomization fixed effects.
} 
Table 7: Structural estimations

\begin{tabular}{|c|c|c|c|}
\hline & $(1)$ & $(2)$ & $(3)$ \\
\hline \multirow[b]{2}{*}{$\mu_{\alpha}$} & $2.327^{* * *}$ & $2.067^{* * *}$ & $1.381^{* *}$ \\
\hline & $(.416)$ & $(0.588)$ & $(0.690)$ \\
\hline \multirow{2}{*}{$\beta_{L}$} & & 0.779 & \\
\hline & & $(0.477)$ & \\
\hline \multirow{2}{*}{$\beta_{H}$} & & 0.008 & \\
\hline & & $(0.791)$ & \\
\hline \multirow{2}{*}{$\beta_{W}$} & & & 1.362 \\
\hline & & & $(0.882)$ \\
\hline \multirow[b]{2}{*}{$\mu_{\zeta}$} & $-2.542^{* * *}$ & $-2.23^{* *}$ & -1.058 \\
\hline & $(0.867)$ & $(0.957)$ & (1.063) \\
\hline \multirow[b]{2}{*}{$\gamma_{L}$} & $0.222 * *$ & -0.901 & $0.218^{* *}$ \\
\hline & $(0.103)$ & $(0.694)$ & $(0.103)$ \\
\hline \multirow{2}{*}{$\gamma_{H}$} & $0.222^{* *}$ & 0.218 & $0.212^{*}$ \\
\hline & $(0.113)$ & (1.111) & $(0.121)$ \\
\hline \multirow{2}{*}{$\gamma_{W}$} & & & -2.04 \\
\hline & & & $(1.262)$ \\
\hline \multirow[b]{2}{*}{$\mu_{\theta}$} & $-3.01^{* * *}$ & $-3.063^{* * *}$ & $-3.549^{*}$ \\
\hline & $(0.857)$ & $(0.854)$ & $(1.075)$ \\
\hline \multirow{2}{*}{$h_{0}$} & $0.351^{* * *}$ & $0.349^{* * *}$ & $0.351^{* * *}$ \\
\hline & $(0.011)$ & $(0.012)$ & $(0.011)$ \\
\hline \multirow{2}{*}{$r$} & $0.207^{* * *}$ & $0.207^{* * *}$ & $0.207^{* * *}$ \\
\hline & $(0.019)$ & $(0.019)$ & $(0.019)$ \\
\hline \multirow[b]{2}{*}{$\sigma_{\alpha}$} & $4.810^{* * *}$ & $4.827^{* * *}$ & $4.774^{* * *}$ \\
\hline & $(1.101)$ & (1.109) & (1.107) \\
\hline \multirow[b]{2}{*}{$\sigma_{\zeta}$} & $0.925^{* * *}$ & $0.963^{* * *}$ & $0.863^{* * *}$ \\
\hline & $(0.228)$ & $(0.223)$ & $(0.264)$ \\
\hline \multirow[b]{2}{*}{$\rho$} & -0.9 & -0.9 & -0.9 \\
\hline & $(-)$ & $(-)$ & $(-)$ \\
\hline Obs. & 8815 & 8815 & 8815 \\
\hline Log lik. & 7585.7101 & -7583.935 & -7583.372 \\
\hline
\end{tabular}

intensive margin, positing direct effects on $\mu_{\alpha}$. Specifically, in Model 2 we restrict our normative statements -which are captured by $\beta_{L}$ and $\beta_{H^{-}}$to have impacts via shifts in the parameter mean. Finally, Model (3) maintains the same structure as Model (1), but allows for the existence of both $\mu_{\alpha}$ and $\mu_{\varsigma}$, or selection effects. That is, shifts in the corresponding parameter means associated with warning (both $\mathrm{W}$ and $\mathrm{OO}$ conditions together). These parameters are labelled as $\beta_{W}$ and $\gamma_{W}$, respectively.

The parameter estimate for $\mu_{\alpha}$ in Model (1) suggests that the marginal utility (willingness to pay) for a packet of CFLs is approximately $\$ 2.33$ for the average household in our sample. Importantly, this estimate provides a potential rationale for why many consumers do not purchase CFLs -ceteris paribus they value them less than the prevailing market price. The negative and highly significant estimate of $\mu_{\varsigma}$-that is, negative social pressure- accounts for the large proportion of subjects not buying anything despite opening the door and having a valuation for a packet of CFLs that exceeds the $\$ 1$ of our low price condition. ${ }^{18}$ As

\footnotetext{
${ }^{18}$ Unfortunately, we are unable to determine what drives this estimate. One possibility is that households dislike being solicited and asked to purchase a packet of light bulbs. A second possibility is that the estimate captures a fixed cost of either having to store the bulbs for future use or replacing existing lighting in the home. Future work should explore the possibilities
} 
the estimated parameter for social pressure in Model (1) is even higher than $\mu_{\alpha}$, the average household in our experiment would only purchase a packet of CFLs if the price was negative (i.e, we paid them to do so). By contrast, both social norms - L and $\mathrm{H}$ - have a positive (and significant) impact on the extensive margin suggesting that the normative statements mitigate spite towards our solicitors and/or increases the valuation households place on the first packet of CFLs purchased. Interestingly, our structural model does not detect any significant difference between the two. This result challenges the claim of the relevance of "proximity", that has been documented in prior work in social psychology which we discussed in Section 4.

The estimate of $\mu_{\theta}$ is negative and highly significant in Model (1) suggesting that individuals do not desire and in fact dislike information on energy efficiency and energy saving strategies. Such dislike accounts for the large proportion of subjects who do not open the door in our warning treatments. To the best of our knowledge, we are the first to document that individuals may actually dislike information on energy efficiency and are willing to take a costly action to avoid receiving such. This result might provide insights into why informational treatments have had little impact on energy savings in the previous literature (see, e.g., Allcott and Sweeney (2016) or Holladay et al. (2019)) and highlight that even though information is supplied, for it to be valuable the market must have demand for the information. In this way, our result has a distant antecedent in considering demand for information in the area of health. For example, people avoid information about their own health (Thornton, 2008; Zanella and Banerjee, 2016), which has been attributed to the fact that people who are ignorant of their health can be more optimistic about it - i.e., it provides a sort of anticipatory utility (or, alternatively, avoiding information may allow them to avoiding anxiety associated with knowledge of bad outcomes, Oster et al., 2013). Viewed in its totality, Model (1) provides two potential explanations for why households eschew the purchase of CFLs despite the documented energy savings: (i) individuals do not seem to care about energy efficiency and actually dislike receiving energy savings information, and (ii) most individuals value CFLs substantially less than the market price- a result we will return to when conducting our policy simulations. In this regard, our structural model provides unique underpinnings for the "energy paradox."

Concerning Model (2), while most of the estimated parameters remain practically unchanged -with specific reference to $\mu_{\alpha}$ and $\mu_{\theta}$ - the dependency of $\mu_{\varsigma}$ on social norm disappears. Moreover, we are unable to establish an effect of the social norms on the intensive margin in that we fail to reject both null hypotheses $H_{0}: \beta_{H}=0$ and $H_{0}: \beta_{L}=0$. Combined with results from Model (1), our structural estimates provide evidence that normative statements operate entirely along the extensive margin. From a positive perspective, this suggests that normative appeals should be modeled as something akin to fixed costs, or "warm glow" that impacts to better understand what drives the low rates of purchase in our experiment. 
choice along the extensive margin but has no impact on the valuation for inframarginal units. Whether and to what extent this insight extends to other domains is an important research agenda.

As for Model (3), we find an interesting result of sorting: it influences both margins, raising the utility of consumption and lowering social pressure (although neither effect turns out to be significant at conventional levels). Directionally, these insights open up an interesting possibility since this is exactly how sorting should impact the treatment effects. For example, in the warning treatment those individuals who are most susceptible to social pressures should sort out so we should find a reduction in the effect of social pressure. Likewise, those with greater valuations should sort in, causing a higher estimated valuation for those that open the door in the warning treatment. In this manner, the structural estimates from Model (3) reveal a potential benefit of a policy approach that is voluntary in nature, allowing people to sort according to their preferences because such an allowance permits a shifting of the distribution effects. ${ }^{19}$

\section{II: Heterogeneity}

Figure 5 sketches $a$ ) the estimated normal distribution of $\alpha$ and $b$ ) the joint (normal) distribution of $\varsigma$ and $\theta$ according to Model (1). As for Panel $a$ ), the estimated relative frequency of households willing to buy 2 packs at the price $p=1(p=5)$ against 1 are set equal to $61 \%(29 \%)$, respectively. These figures match exactly the observed frequencies of Table 5.

\footnotetext{
${ }^{19}$ In terms of model fit, the three functionals are not nested, so one cannot use nested test statistics to test between them. However, one can use the Akaike Information Criterion (AIC) or the Bayesian Information Criterion (BIC) to provide a ranking of the various functionals (Amemiya, 1980). Both criteria In deal with the trade-off between the goodness of fit of the model and the simplicity of the model (i.e., the number of parameters to be estimated). In this respect under both criteria, Model (1) (Model (3)) [Model (2)] ranks first (second) [third], respectively. This is some confirmation that the most parsimonious model tailored upon the reduced-form regressions is also the one which fits best our experimental evidence.
} 
Figure 5: Estimated distributions of $\alpha, \varsigma$ and $\theta$ (Model II)

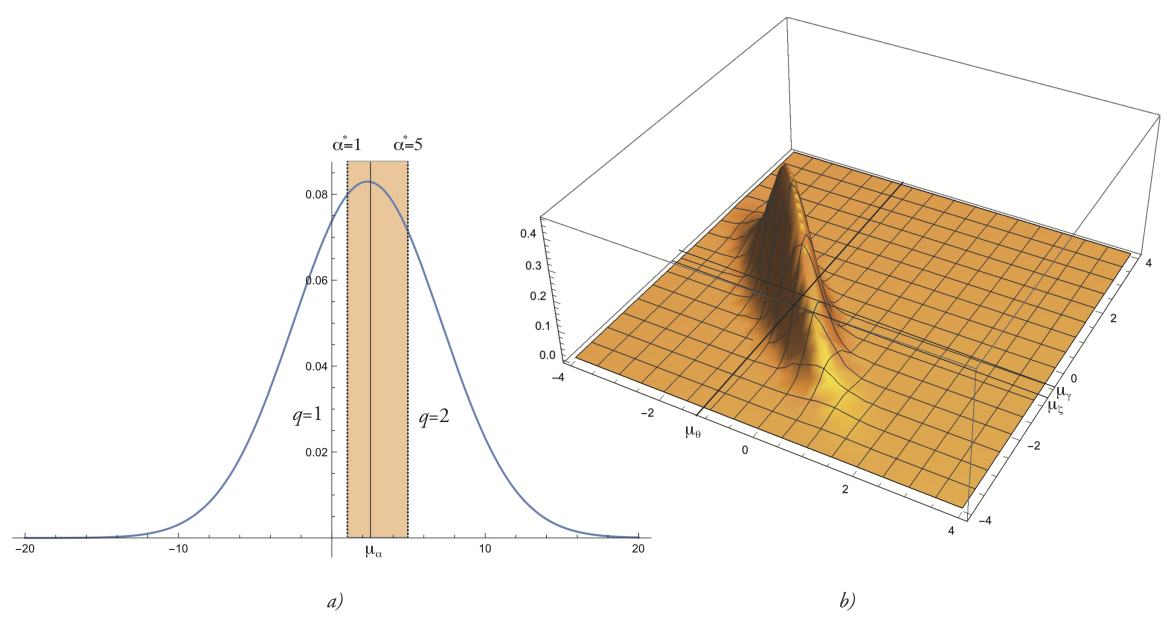

Note: Panel $a$ ) shows the estimated normal distribution of $\alpha$. Panel $b$ ) the joint (normal) distribution of $\varsigma$ and $\theta$ according to Model (1).

As we know from Table $7, \varsigma$ and $\theta$ display a very high negative correlation, which reflects the shape of the joint distribution. ${ }^{20}$ The estimated probability of opening the door in the No Warning condition, $h_{0}$, is estimated around $35 \%$ and follows closely the observed frequency (37\%, see Table 2). By the same token, the probability of noticing the flyer, $r$, is lower than the corresponding estimate in DLM (20\% vs. 32\%). Then, the ex-ante probability of not opening the door conditional on warning derived from Model (1) is then $(1-r)\left(1-h_{0}\right)+r\left(1-\beta_{2}\left(\mu_{\alpha}, \mu_{\varsigma}, \mu_{\theta}\right)\right)=32 \%$ (compare with Table 2$)$.

\section{III: Willingness to Pay and Policy Simulations}

We now take deeper advantage of our structural model to estimate expected changes in demand at prices outside the narrow range of parameters implemented in our field experiment. Table 8 reports the "simulated demand" derived by Models (1) to (3) for a wider range of prices, from -1 to 5 , than those tested in the field experiment. In doing so, we are able to simulate the effect of policies whereby CFLs are given to households at no cost, or are actually subsidized. Furthermore, we are able to examine the complete interaction of prices and social norms. For example, whether normative statements on the usage of others affects observed price elasticities, and the role of sorting as induced by our warning treatments. We can derive such effects across our three model specifications. As such, we are able to examine the existence of a "social norm effect" and

\footnotetext{
${ }^{20}$ We estimated the models by fixing the value of the correlation coefficient, $\rho$, from a finite grid. This is why the associated standard errors have not been reported.
} 
simulate it at different price levels. We are also able to examine how the effectiveness of any policy option is impacted by sorting and subsequent changes in the distribution of types that are exposed to the policy.

As we allow the effect of prices and social norms to vary along the extensive and intensive margins, we simulate and report the effects along the two margins separately - i.e., we allow different elasticities along the extensive and intensive margins. Moreover, all figures in Table 8 represent relative frequency of purchases conditional on opening the door, and should thus be interpreted as the effect of a treatment on the treated. In this regard, we are unable to directly simulate the effect of a policy that allows sorting. Rather, we are able to examine whether the effect of price changes and normative appeals is impacted by changes in the set of people exposed to the policy across the warning and no-warning conditions. ${ }^{21}$

Figures in Table 8 can be read as follows. The table is divided into four distinct blocks that capture whether households were warned about the solicitation and whether the household was provided a normative statement on the adoption decisions of others. For example, the first block corresponds to our baseline treatment whereby households are not warned in advance of the solicitation request and are not provided any information about the adoption decisions of others whereas the final block corresponds to the predicted frequencies for households that were warned in advance of the solicitation and were provided information on the adoption decisions of others upon opening the door.

Within each block, we calculate predicted frequencies for five different price levels - the prevailing market price for a package of CFLs at the time of our experiment $(\$ 5)$, two prices that reflect partial subsidies on the purchase ( $\$ 3$ and $\$ 1$ ), a full subsidy on purchase that would correspond to giving away the package $(\$ 0)$, and a negative price that would correspond to a policy of fully subsidizing the purchase of CFLs and providing households a tax credit or similar rebate (of $\$ 1$ ) should they accept the package. The first column of the table presents results that simulate demand using parameter estimates from Model (1) in Table 7 whereas the second and third columns present simulations that rely upon parameter estimates from Models (2) and (3) of Table 7, respectively. Within each column, we present two distinct frequencies - the likelihood that a household who opens the door elects to purchase at least one package of CFLs (the extensive margin) and the conditional likelihood of purchasing a second package (the intensive margin).

\footnotetext{
${ }^{21}$ Of course, one could use estimates on the likelihood of opening the door to recover the effect of sorting and the total effect of policy options in the presence of sorting. By the same token, we condition intensive margin effects on the set of individuals that purchased at least one package of CFLs but can easily recover the total effect of any policy change from the information reported in Table 8 .
} 
Table 8: Counterfactuals (1)

\begin{tabular}{|c|c|c|c|c|c|c|c|c|}
\hline & & & \multicolumn{2}{|c|}{ Model (1) } & \multicolumn{2}{|c|}{ Model (2) } & \multicolumn{2}{|c|}{ Model (3) } \\
\hline $\bar{W}$ & Social Norms & Price & Ext. Marg. & Int. marg. & Ext. Marg. & Int. marg. & Ext. Marg. & Int. marg. \\
\hline \multirow{5}{*}{ No } & \multirow{5}{*}{ No } & 5 & 0.042 & 0.289 & 0.042 & 0.274 & 0.036 & 0.224 \\
\hline & & 3 & 0.069 & 0.444 & 0.069 & 0.425 & 0.059 & 0.367 \\
\hline & & 1 & 0.114 & 0.608 & 0.113 & 0.588 & 0.096 & 0.531 \\
\hline & & 0 & 0.145 & 0.685 & 0.145 & 0.666 & 0.123 & 0.613 \\
\hline & & -1 & 0.183 & 0.755 & 0.182 & 0.737 & 0.156 & 0.691 \\
\hline \multirow{5}{*}{ No } & \multirow{5}{*}{ Yes } & 5 & 0.066 & 0.289 & 0.066 & 0.301 & 0.063 & 0.224 \\
\hline & & 3 & 0.104 & 0.444 & 0.104 & 0.457 & 0.098 & 0.367 \\
\hline & & 1 & 0.162 & 0.608 & 0.163 & 0.619 & 0.152 & 0.531 \\
\hline & & 0 & 0.201 & 0.685 & 0.203 & 0.695 & 0.188 & 0.613 \\
\hline & & -1 & 0.248 & 0.755 & 0.249 & 0.763 & 0.232 & 0.691 \\
\hline \multirow{5}{*}{ Yes } & \multirow{5}{*}{ No } & 5 & 0.042 & 0.289 & 0.042 & 0.274 & 0.046 & 0.318 \\
\hline & & 3 & 0.069 & 0.444 & 0.069 & 0.425 & 0.075 & 0.479 \\
\hline & & 1 & 0.114 & 0.608 & 0.113 & 0.588 & 0.124 & 0.643 \\
\hline & & 0 & 0.145 & 0.685 & 0.145 & 0.666 & 0.158 & 0.717 \\
\hline & & -1 & 0.183 & 0.755 & 0.182 & 0.737 & 0.199 & 0.784 \\
\hline \multirow{5}{*}{ Yes } & \multirow{5}{*}{ Yes } & 5 & 0.066 & 0.289 & 0.066 & 0.301 & 0.071 & 0.318 \\
\hline & & 3 & 0.104 & 0.444 & 0.104 & 0.457 & 0.112 & 0.479 \\
\hline & & 1 & 0.162 & 0.608 & 0.163 & 0.619 & 0.175 & 0.643 \\
\hline & & 0 & 0.201 & 0.685 & 0.203 & 0.695 & 0.217 & 0.717 \\
\hline & & -1 & 0.248 & 0.755 & 0.249 & 0.763 & 0.266 & 0.784 \\
\hline
\end{tabular}

We begin by exploring the effect of policy changes as simulated using estimates from Model (1). Recall that, under this specification, prices are allowed to influence choice along both the extensive and intensive margins whereas social norms are restricted to impact behavior along only the extensive margin. Hence, estimates for the proportion of households that purchase at least one pack of CFLs at any given price differ across the first and second blocks of the table but there are no differences in intensive margin effects across these two blocks. Similarly, as Model (1) does not condition behavior on our warning treatments, there are no differences in predicted probabilities across blocks one and three (two and four) which differ only in whether or not the estimates are conditioned on warning the household in advance of the solicitation request.

We first examine the effects of a policy that subsidizes the purchase of CFLs and thus lower the per unit price. As noted in the first block of Table 8 , it is hard to stimulate the purchase of CFLs through price changes. For example, we estimate that approximately 4.2 percent of households would purchase at least one package of CFLs at the prevailing market price (\$5). If, instead, we were to offer a 40 percent (or $\$ 2$ ) subsidy on the purchase of a package, the probability of a household purchasing at least one package would only increase by 2.7 percentage points. Increasing the subsidy by an additional $\$ 2$ would lead to an approximate 4.5 percentage point increase in the likelihood a household purchases at least one package. In fact, even if we were to fully subsidize the purchase of CFLs and offer to give away packages for free, only 14.5 percent of households would take up the offer. That such a significant fraction of households would turn down a "free" package of CFLs suggests that such households view them as inferior to (or imperfect subsititute for) the 
existing stock of lightbulbs in their home. ${ }^{22}$

Comparing the effect of price changes along the intensive margin reveals a more elastic pattern of behavior. For example, we estimate that approximately 28.9 percent of the households who purchase CFLs at the prevailing market price $(\$ 5)$ would buy multiple packages. If, instead, we were to offer a $\$ 2$ subsidy on the price per pack, the conditional probability of a household purchasing a second package of CFLs would increase by approximately 15.5 percentage points. Combined with the estimated extensive margin effects, we would thus expect a $\$ 2$ per pack subsidy to generate a 35 unit increase in the overall number of packages purchased per one thousand people. ${ }^{23}$ Yet, even in this case if we were to give away packages for free, only 68.5 percent of those who take up the offer would demand a second package which, when combined with the effects along the extensive margin, would generate a 179 unit increase in the overall number of packages purchased per one thousand people. ${ }^{24}$

We next examine the effect of an alternate policy, grounded in behavioral economics, that would provide households information on the fraction of others in their area that report owning and using at least one CFL. As the effects of such policies in Model (1) are restricted to the extensive margin, we focus our discussion on the extensive margin effects and subsequent changes in the likelihood that a household will elect to purchase at least one package of CFLs at different price levels. As noted in the second block of Table 8, the inclusion of normative information leads to an approximate 35.5 to 57.1 percent increase in the likelihood a household elects to purchase at least one package of CFLs with the effect more pronounced at higher price levels. For example, at a price of $\$ 5$ per package, provision of our normative information is estimated to generate an approximate 57.1 percent (2.4 percentage point) increase in the likelihood a household purchase a package of CFLs. At a price of $\$ 1$ per package, in contrast, providing households normative information is estimated to generate an approximate 42.1 percent (4.8 percentage point) increase in the likelihood of purchase.

Results using estimates from our other two specifications are qualitatively similar. However, it is worth noting that allowing households to sort - as in our warning treatments - does alter the effectiveness of our various policy instruments. For example, comparing estimates for Model (3) across the first and third blocks, the effect of a $\$ 2$ subsidy on the per package price of CFLs would nearly double if households were allowed to sort. Without the ability to sort, such a subsidy would generate an approximate 26 unit increase in the overall number of packages purchased per one thousand people. If, instead, households were allowed to sort, such a subsidy would generate an approximate 70 unit increase in the overall number of packages purchased

\footnotetext{
${ }^{22}$ While we are unable to identify why the households in our study dislike CFLs, our findings are consistent with concerns that fluorescent lights do not work well in colder temperatures and take longer to achieve full brightness.

${ }^{23}$ At the prevailing price, our estimates suggest that we would sell approximately 65 packages per 1000 households. At $\$ 3$ per package, we would expect to sell approximately 100 packages per 1000 households.

${ }^{24}$ Our estimates thus suggest that we would have to spend somewhere in the range of $\$ 5.71$ to $\$ 6.82$ to stimulate the purchase of one additional package of CFLs.
} 
per one thousand people. ${ }^{25}$ From a policy perspective, allowing households to sort, reduces the necessary budget to stimulate the purchase of an additional package of CFLs by almost a dollar - $\$ 4.40$ per additional package in the warning condition versus $\$ 5.38$ per additional package in the no warning condition.

In contrast, allowing households the ability to sort, reduces the effectiveness of social norms. For example, in our no warning condition, our normative statement increases the likelihood a household purchases a package of CFLs by approximately 75 percent (2.7 percentage points) when the price is $\$ 5$ per package. In our warning condition, however, including a normative statement only increases the likelihood a household purchases a package of CFLs by 54 percent (2.5 percentage points). Interestingly, such differences are even more pronounced at lower prices. These results hold import for the recent discussion regarding scaling and generalizability of experimental results. As Al-Ubaydli et al. (2017, 2019) show, the properties of the population and situation importantly influence whether and to what extent empirical results from original small-scale studies transfer to a larger setting. In this case, our results show that sorting in and of itself leads to dramatically different policy interpretations. For policymakers interested in understanding benefit cost ratios at scale, this result reveals the importance of a rarely discussed activity, sorting.

In this spirit, we can also use our structural model to determine the maximum prices that could be charged to ensure a target frequency of adoption. Results from these simulations are presented in Table 9, and can be read as follows. As with our prior discussion, the table is divided into four distinct blocks that capture whether households were warned about the solicitation and whether they were provided a normative statement about the adoption decisions of others. Within each block, we calculate the maximum price that could be charged given a target that $X=1,5,10,25,50$ percent of households would purchase at least one package of CFLs (extensive margin) or an additional one (intensive margin). The first column of Table 9 presents results that simulate demand using parameter estimates from Model (1) in Table 7 whereas the second and third columns present simulations that rely upon estimates from Models (2) and (3) of Table 7.

\footnotetext{
${ }^{25}$ In the no warning condition, the estimated number of packages purchased at $\$ 5$ (\$3) is 44 units (70 units) respectively. If, instead, we allow people to sort and condition the estimates on whether or not households were warned, the expected number of packages purchased at $\$ 5(\$ 3)$ is 60 units (110 units) respectively.
} 
Table 9: Counterfactuals (2)

\begin{tabular}{|c|c|c|c|c|c|c|c|c|}
\hline & & & \multicolumn{2}{|c|}{ Model (1) } & \multicolumn{2}{|c|}{ Model (2) } & \multicolumn{2}{|c|}{ Model (3) } \\
\hline $\mathrm{W}$ & Social Norms & Target & Ext. Marg. & Int. marg. & Ext. Marg. & Int. marg. & Ext. Marg. & Int. marg. \\
\hline \multirow{5}{*}{ No } & \multirow{5}{*}{ No } & $1 \%$ & $\$ 10.90$ & $\$ 13.51$ & $\$ 10.97$ & $\$ 13.39$ & $\$ 10.30$ & $\$ 12.48$ \\
\hline & & $5 \%$ & $\$ 4.32$ & $\$ 10.24$ & $\$ 4.35$ & $\$ 10.08$ & $\$ 3.66$ & $\$ 9.23$ \\
\hline & & $10 \%$ & $\$ 1.53$ & $\$ 8.49$ & $\$ 1.53$ & $\$ 8.31$ & $\$ 0.84$ & $\$ 7.49$ \\
\hline & & $25 \%$ & $\$-2.41$ & $\$ 5.57$ & $\$-2.44$ & $\$ 5.36$ & $\$-3.13$ & $\$ 4.59$ \\
\hline & & $50 \%$ & $\$-6.34$ & $\$ 2.32$ & $\$-6.37$ & $\$ 2.08$ & $\$-7.05$ & $\$ 1.37$ \\
\hline \multirow{5}{*}{ No } & \multirow{5}{*}{ Yes } & $1 \%$ & $\$ 13.33$ & $\$ 13.51$ & $\$ 13.19$ & $\$ 13.78$ & $\$ 12.71$ & $\$ 12.48$ \\
\hline & & $5 \%$ & $\$ 6.28$ & $\$ 10.24$ & $\$ 6.22$ & $\$ 10.47$ & $\$ 5.63$ & $\$ 9.23$ \\
\hline & & $10 \%$ & $\$ 3.19$ & $\$ 8.49$ & $\$ 3.18$ & $\$ 8.70$ & $\$ 2.51$ & $\$ 7.49$ \\
\hline & & $25 \%$ & $\$-1.04$ & $\$ 5.57$ & $\$-1.01$ & $\$ 5.75$ & $\$-1.75$ & $\$ 4.59$ \\
\hline & & $50 \%$ & $\$-5.07$ & $\$ 2.32$ & $\$-5.02$ & $\$ 2.47$ & $\$-5.79$ & $\$ 1.37$ \\
\hline \multirow{5}{*}{ Yes } & \multirow{5}{*}{ No } & $1 \%$ & $\$ 10.90$ & $\$ 13.51$ & $\$ 10.97$ & $\$ 13.39$ & $\$ 11.17$ & $\$ 13.85$ \\
\hline & & $5 \%$ & $\$ 4.32$ & $\$ 10.24$ & $\$ 4.35$ & $\$ 10.08$ & $\$ 4.64$ & $\$ 10.59$ \\
\hline & & $10 \%$ & $\$ 1.53$ & $\$ 8.49$ & $\$ 1.53$ & $\$ 8.31$ & $\$ 1.88$ & $\$ 8.86$ \\
\hline & & $25 \%$ & $\$-2.41$ & $\$ 5.57$ & $\$-2.44$ & $\$ 5.36$ & $\$-2.04$ & $\$ 5.97$ \\
\hline & & $50 \%$ & $\$-6.34$ & $\$ 2.32$ & $\$-6.37$ & $\$ 2.08$ & $\$-5.95$ & $\$ 2.75$ \\
\hline \multirow{5}{*}{ Yes } & \multirow{5}{*}{ Yes } & $1 \%$ & $\$ 13.33$ & $\$ 13.51$ & $\$ 13.19$ & $\$ 13.78$ & $\$ 13.57$ & $\$ 13.85$ \\
\hline & & $5 \%$ & $\$ 6.28$ & $\$ 10.24$ & $\$ 6.22$ & $\$ 10.47$ & $\$ 6.57$ & $\$ 10.59$ \\
\hline & & $10 \%$ & $\$ 3.19$ & $\$ 8.49$ & $\$ 3.18$ & $\$ 8.70$ & $\$ 3.51$ & $\$ 8.86$ \\
\hline & & $25 \%$ & $\$-1.04$ & $\$ 5.57$ & $\$-1.01$ & $\$ 5.25$ & $\$-0.68$ & $\$ 5.97$ \\
\hline & & $50 \%$ & $\$-5.07$ & $\$ 2.23$ & $\$-5.02$ & $\$ 2.47$ & $\$-4.69$ & $\$ 2.75$ \\
\hline
\end{tabular}

Consistent with our previous analysis, we consider two distinct policy instruments - price changes (subsidies) and the use of a nudge that provides information on the fraction of households in one's area that report having installed at least one CFL in their home -and examine whether the effectiveness of such instruments are effected when we warn households and thus allow sorting.

Considering the extensive margin, we begin by exploring the effect of policy changes as simulated using estimates from Model (1). As noted in the first column of Table 9, any policy that targets adoption rates in excess of 25 percent would require that policy makers offer households compensation for accepting a package of CFLs. For example, estimates from the first block suggest that we would have to offer compensation of approximately $\$ 2.41$ if we wanted adoption rates of 25 percent. If instead, our target was for the median household to purchase a package of CFLs, compensation of approximately $\$ 6.34$ would be required. Provision of social information, however, reduces the amount of compensation required to meet adoption targets in excess of 25 percent. As noted in the second block of Table 9, the amount of compensation required to ensure a 25 (50) percent adoption threshold amongst households that are provided social information falls to $\$ 1.04$ (\$5.07) respectively.

Introducing the ability to sort, as in Model (3), also serves to reduce the level of compensation required to achieve target adoption rates in excess of 25 percent. For example, in the absence of social information, the compensation required to induce 25 percent of households to adopt falls from $\$ 3.13$ in our no warning 
condition to $\$ 2.04$ when households can sort. ${ }^{26}$ We observe a similar effect of sorting on the level of compensation required in the presence of social information. For example, the level of compensation required to achieve a 25 percent adoption rate in the presence of social information falls from $\$ 2.04$ to $\$ 0.68$ when households are allowed to sort.

We now turn our attention to intensive margins where, by construction, the median household in the baseline condition evaluates the purchase of an additional package exactly as what the estimates of $\mu_{\alpha}$ in Table 8 indicate, for all models. Also notice that the impact of social norms (Model 2) and sorting (Model 3 ) are in line with those we discussed for the extensive margins, but lower in magnitude. As for social norms, the presence of a social norm statement can act as a substitute for a price reduction that ranges from 3 to $16 \%$ (depending on the target of adoption). By comparison, sorting (Model 3) has an even greater impact: it substitutes for a price reduction that ranges from 10 to $50 \%$ (again, depending on the target: the lower the target, the lower the reduction).

As a whole, our policy simulations questions the cost effectiveness of policies to promote the adoption of CFLs. Demand for CFLs is low and a substantial fraction of households appear to dislike such technologies and would require compensation in order to accept a package of CFLs. This opens up the debate of whether one should consider CFLs as a perfect substitute for incandescent lights-our estimates suggest that a majority of households view them as an inferior technology. ${ }^{27}$ Moreover, while social information and the ability to sort do serve to stimulate demand, such effects do little to reduce the costs required to achieve adoption rates in excess of 25 percent.

\section{Conclusions}

The effects of innovation on economic growth are importantly moderated by the diffusion rates of new technologies. Viewed broadly, our contribution is to highlight the import of both economic and non-economic factors to the diffusion process. Methodologically, we show the power of designing a field experiment that is tightly connected to a structural model. Narrowly, our study is motivated by the potential (and need) for reducing energy consumption by residential households. Residential users account for approximately 21 percent of all greenhouse gas emissions in the United States (U.S. Energy Information Administration). Changing patterns of electricity consumption in the residential sector is necessary if the United States is to

\footnotetext{
${ }^{26}$ We observe a similar reduction in the level of compensation required to induce the median household to accept a package of CFLs. In the absence of social information, the median household in our no warning condition requires $\$ 7.05$ to accept a package of CFL's whereas counterparts who are allowed to sort require only $\$ 5.95$ to accept a package.

${ }^{27}$ Although outside the scope of our current analysis, this result has implications for work on the energy paradox. If households view CFLs as an inferior technology, it could be a rational decision to eschew their purchase even though doing so would save the household money on monthly energy bills.
} 
achieve former President Obama's goal of reducing greenhouse gas emissions by $28 \%$ by 2020. Although social comparisons have proven an effective means to manage residential electricity demand (see e.g. Allcott, 2009; Ayres and Ayres, 2009), the effects of such programs are far less than what is needed to achieve Obama's emissions targets. In this regard, we view policies designed to promote technology adoption as an important complement to such programs.

We focus our analysis on CFLs as the rate of CFL adoption and diffusion throughout the United States satisfied two primary conditions necessary to be classified a technology suffering from the energy paradox - CFLs have had slow rates of diffusion while being economically rational to purchase. ${ }^{28}$ Yet, the results from the field experiment could be used to inform adoption programs for other environmental technologies, such as low flow shower heads, hybrid and electric cars, or technology involved with energy smart grids such as smart meters and in-home displays. Importantly, our research provides the first direct comparison of prices and social norms, since our approach affords an apples-to-apples comparison in the context of a single, large-scale field experiment. In doing so, our approach provides greater understanding of the motives surrounding consumer adoption and should help inform policy makers interested in promoting the adoption of green technologies as a means to achieve Obama's emissions target.

Although market-based environmental policies have been on the minds of economists since Pigou's seminal work on welfare in 1912, subsidizing new environmental technologies to encourage adoption stands as a somewhat controversial approach under the standard economic assumption of informed rational agents. This paper does not explore market imperfections or whether subsidizing new technology could be seen as economically rational. Rather, we operate under an assumption that sufficient externalities exist to justify public policy, or, as stated previously in Jaffe and Stavins (1994): "If there are significant externalities associated with burning fossil fuels, however, then the paradox becomes much more important. Indeed, the existence of such externalities could justify public policies to reduce energy use." We feel comfortable in this assumption given that pollution continues to not be fully priced in to the market, presenting society a cost that markets have not internalized. Moreover there is a growing literature on behavioral welfare economics (e.g. Allcott and Taubinsky, 2015, see Section 2 for a discussion of the relevant literature) that considers that individuals are subject to internalities (so that they do not consider all the consequences for themselves of their own decisions), what would further justify the interventions.

\footnotetext{
${ }^{28}$ The Department of Energy's "CFL Market Profile" released in March, 2009, found that only $11 \%$ of the light sockets feasible for CFLs in U.S. households were being used by CFLs, although $70 \%$ of U.S. households did have at least one CFL. Under varying assumptions, the upfront costs of CFLs will be recouped in two to four months due to energy cost savings. For example, assuming energy prices of $\$ 0.12$ per kilowatt hour and a typical assumption of 1,142 hours per year of usage per light bulb results in a per month charge of $\$ 0.69$ for a 60 watt incandescent light bulb versus $\$ 0.34$ for a 60 watt "equivalent" CFL at 14 watts, netting a per month savings of $\$ 0.35$. Although the savings is small, the difference in upfront costs are now typically small, ranging between $\$ 0.25$ and $\$ 2.00$.
} 
Non-pecuniary techniques to motivate residential energy conservation used in research by social psychologists and behavioral economists have generally focused on changing energy usage behavior rather than focusing on encouraging adoption of energy efficient products. This is evident in broad reviews of the existing literature such as Abrahamse et al. (2005), as well as more recent research such as Schultz et al. (2007), Allcott (2009), List and Price (2016), or Price (2014). However, we chose to focus on motivating technology adoption as a specific behavioral change in order to avoid the issues that cause the beneficial energy conservation results to lessen over time, such as the "boomerang" effect and mean reversion. It is possible that adjustments in lighting usage caused our study to not result in the full energy reduction potential. We attempt to address this by conducting follow-up interviews but this should be considered more fully in future research provided that energy usage data can be obtained.

In particular, we believe the importance of heterogeneity should be explicitly addressed in interventions such as ours. Our structural estimation results in Section 5 show that there is substantial heterogeneity in individual characteristics and, even more, that there is a substantial negative correlation between curiosity and social pressure. This suggest that interventions that ignore heterogeneity will often under-perform those that take it into account, for example by assigning treatments to individuals according to observed and/or elicited characteristics. This would allow individuals who would benefit from treatment to receive it, while those who would be hurt can be assigned to a control group. We view this approach as an exciting area of future research.

Our results suggest that both prices and social norms impact the decision to adopt new technologies. Yet, only prices impact the consumer's quantity decision. Hence, price and social norms affect behavior along different margins: whereas social norms affect behavior along the extensive margin, prices affect behavior along both margins. Price and social norms working on different margins has important implications when considering how to motivate consumers to utilize new environmental technologies. As we have discussed in Section 3, our design did not allow us to disentangle the effects of the private valuation for the CFLs from those of altruism. However, in future research we will attempt to analyze these two channels, by using treatments that prime private economic concerns vs. public environmental concerns.

The results suggest that the use of price reductions through subsidies should be considered when there is a desire to encourage further diffusion of the technology, while social-psychology motivations should be considered when attempting to encourage adoption. This intriguing result is intuitive and could be easily explored further in future research. 


\section{References}

Abrahamse, W., Steg, L., Vlek, C. and Rothengatter, T. (2005) A review of intervention studies aimed at household energy conservation, Journal of environmental psychology, 25, 273-291.

Acland, D. and Levy, M. (2016) Habit formation and Naivete in gym attendance: evidence from a field experiment, Working paper.

Aghion, P. and Howitt, P. (1992) The schumpeterian approach to technical change and growth, in Economic Growth in the World Economy: Symposium, vol. 1993.

Al-Ubaydli, O., List, J. A. and Suskind, D. (2019) The science of using science: Towards an understanding of the threats to scaling experiments, Tech. rep., National Bureau of Economic Research.

Al-Ubaydli, O., List, J. A. and Suskind, D. L. (2017) What can we learn from experiments? understanding the threats to the scalability of experimental results, American Economic Review, 107, 282-86.

Allcott, H. (2009) Social norms and energy conservation working paper, Massachusetts Institute of Technology (MIT), Cambridge, MA https://files. nyu. edu/ha32/public/research. html.

Allcott, H. (2011) Social norms and energy conservation, Journal of Public Economics, 95, 1082-1095.

Allcott, H. and Greenstone, M. (2012) Is there an energy efficiency gap?, The Journal of Economic Perspectives, 26, 3-28.

Allcott, H., Mullainathan, S. and Taubinsky, D. (2014) Energy policy with externalities and internalities, Journal of Public Economics, 112, 72-88.

Allcott, H. and Rogers, T. (2014) The Short-Run and Long-Run Effects of Behavioral Interventions : Experimental Evidence from Energy Conservation , American Economic Review, 104, 3003-3037.

Allcott, H. and Sweeney, R. L. (2016) The role of sales agents in information disclosure: evidence from a field experiment, Management Science, 63, 21-39.

Allcott, H. and Taubinsky, D. (2015) Evaluating behaviorally-motivated policy: Experimental evidence from the lightbulb market, American Economic Review, 105, 2501-2538.

Alós-Ferrer, C., García-Segarra, J. and Ritschel, A. (2018) Performance curiosity, Journal of Economic Psychology, 64, 1-17.

Amemiya, T. (1980) Selection of regressors, International economic review, pp. 331-354.

Ayres, R. U. and Ayres, E. H. (2009) Crossing the energy divide: moving from fossil fuel dependence to a clean-energy future, Pearson Prentice Hall.

Baicker, K., Mullainathan, S. and Schwartzstein, J. (2015) Behavioral hazard in health insurance, Quarterly Journal of Economics.

Bandiera, O. and Rasul, I. (2006) Social Networks and Technology Adoption in Northern Mozambique, The Economic Journal, 116, 869-902.

Bernard, J. C., Schulze, W. et al. (2005) The next new thing: curiosity and the motivation to purchase novel products, Economics Bulletin, 3, 1-8. 
Brandon, A., Ferraro, P. J., List, J. A., Metcalfe, R. D., Price, M. K. and Rundhammer, F. (2016) Do The Effects of Social Nudges Persist? Theory and Evidence from 38 Natural Field Experiments, Working Paper.

Charness, G. and Gneezy, U. (2009) Incentives to exercise, Econometrica, 77, 909-931.

Charness, G., Levin, D. et al. (2003) Bayesian updating vs. reinforcement and affect: A laboratory study, Levines Bibliography 666156000000000180, UCLA Department of Economics.

Chen, J., Humphreys, M. and Modi, V. (2010) Technology diffusion and social networks: Evidence from a field experiment in Uganda, Manuscript, Columbia University.

Chetty, R. (2008) Sufficient Statistics for Welfare Analysis: A Bridge Between Structural and Reduced-Form Methods, Annual Review of Economics, 1, 451-488.

Chetty, R. (2015) Behavioral Economics and Public Policy: A Pragmatic Perspective, American Economic Review, 105, 1-33.

Cialdini, R. B. (2007) Descriptive social norms as underappreciated sources of social control, Psychometrika, 72, 263.

Comin, D. and Hobijn, B. (2004) Cross-country technology adoption: making the theories face the facts, Journal of monetary Economics, 51, 39-83.

Conley, T. G. and Udry, C. R. (2010) Learning about a new technology: Pineapple in Ghana, The American Economic Review, 100, 35-69.

Conlin, M., O’Donoghue, T. and Vogelsang, T. J. (2007) Projection bias in catalog orders, american economic Review, 97, 1217-1249.

DellaVigna, S., List, J. A. and Malmendier, U. (2012) Testing for Altruism and Social Pressure in Charitable Giving, The Quarterly Journal of Economics, 127, 1-56.

DellaVigna, S., List, J. A., Malmendier, U. and Rao, G. (2016a) Estimating social preferences and gift exchange at work, Tech. rep., National Bureau of Economic Research.

DellaVigna, S., List, J. A., Malmendier, U. and Rao, G. (2016b) Voting to tell others, The Review of Economic Studies, 84, 143-181.

Desjardins, J. (2018) A brief history of technology, World Economic Forum https://www.weforum.org/agenda/2018/02/the-rising-speed-of-technological-adoption.

EPA, U. (2017) Light bulb revolution: Epa predicts widespread consumer adoption of led lighting by 2020 if utility programs persist., Tech. rep., EPA Office of Air and Radiation, Climate Protection Partnerships Division.

Fernald, J. G. and Jones, C. I. (2014) The future of us economic growth, American economic review, 104, $44-49$.

Ferraro, P. J., Miranda, J. J. and Price, M. K. (2011) The persistence of treatment effects with normbased policy instruments: evidence from a randomized environmental policy experiment, The American Economic Review, 101, 318-322. 
Ferraro, P. J. and Price, M. K. (2013) Using Nonpecuniary Strategies to Influence Behavior: Evidence from a Large-Scale Field Experiment, Review of Economics and Statistics, 95, 64-73.

Foster, A. D. and Rosenzweig, M. R. (2010) Microeconomics of technology adoption, Annu. Rev. Econ., 2, 395-424.

Gerarden, T. D., Newell, R. G. and Stavins, R. N. (2017) Assessing the energy-efficiency gap, Journal of Economic Literature, 55, 1486-1525.

Gillingham, K., Keyes, A. and Palmer, K. (2018) Advances in evaluating energy efficiency policies and programs, Annual Review of Resource Economics.

Gillingham, K., Newell, R. G. and Palmer, K. (2009) Energy efficiency economics and policy, Annu. Rev. Resour. Econ., 1, 597-620.

Gillingham, K. and Palmer, K. (2014) Bridging the energy efficiency gap: Policy insights from economic theory and empirical evidence, Review of Environmental Economics and Policy, 8, 18-38.

Giné, X., Karlan, D. and Zinman, J. (2010) Put your money where your butt is: a commitment contract for smoking cessation, American Economic Journal: Applied Economics, pp. 213-235.

Goldstein, N. J., Cialdini, R. B. and Griskevicius, V. (2008) A room with a viewpoint: Using social norms to motivate environmental conservation in hotels, Journal of consumer Research, 35, 472-482.

Griliches, Z. (1957) Hybrid corn: An exploration in the economics of technological change, Econometrica, Journal of the Econometric Society, pp. 501-522.

Hall, B. H. (2004) Innovation and diffusion, Tech. rep., National Bureau of Economic Research.

Handel, B. R. (2013) Adverse Selection and Inertia in Health Insurance Markets: When Nudging Hurts, American Economic Review, 103, 2643-2682.

Harrison, G. W. and List, J. A. (2004) Field Experiments, Journal of Economic Literature, 42, $1009-1055$.

Hausman, J. A. and Wise, D. A. (1976) A conditional probit model for qualitative choice: discrete decisions recognizing interdependence and heterogenous preferences.

Herrnstein, R. J., Loewenstein, G. F., Prelec, D. and Vaughan, W. (1993) Utility maximization and melioration: Internalities in individual choice, Journal of Behavioral Decision Making, 6, 149-185.

Holladay, S., LaRiviere, J., Novgorodsky, D. and Price, M. (2019) Prices versus nudges: What matters for search versus purchase of energy investments?, Journal of Public Economics, 172, 151-173.

Jaffe, A. B., Newell, R. G. and Stavins, R. N. (2002) Environmental policy and technological change, Environmental and resource economics, 22, 41-70.

Jaffe, A. B. and Stavins, R. N. (1994) The energy paradox and the diffusion of conservation technology, Resource and Energy Economics, 16, 91-122.

Jaffe, A. B. and Stavins, R. N. (1995) Dynamic incentives of environmental regulations: The effects of alternative policy instruments on technology diffusion, Journal of environmental economics and management, 29, S43-S63.

Jimenez-Gomez, D. (2019) Nudging and Phishing: A Theory of Behavioral Welfare Economics, Working Paper. 
Jones, C. I. (2002) Sources of us economic growth in a world of ideas, American Economic Review, 92, 220-239.

Laibson, D., Repetto, A. and Tobacman, J. (2007) Estimating discount functions with consumption choices over the lifecycle, Tech. rep., National Bureau of Economic Research.

Lapinski, M. K. and Rimal, R. N. (2005) An explication of social norms, Communication Theory, 15, 127147.

Lefèvre, N., de T'Serclaes, P. and Waide, P. (2006) Barriers to technology diffusion: the case of compact fluorescent lamps, Joint OECD and IEA Paper, Paris, pp. 1-35.

List, J. A. and Price, M. K. (2016) The use of field experiments in environmental and resource economics, Review of Environmental Economics and Policy, 10, 206-225.

Litman, J., Hutchins, T. and Russon, R. (2005) Epistemic curiosity, feeling-of-knowing, and exploratory behaviour, Cognition \& Emotion, 19, 559-582.

Loewenstein, G. (1994) The psychology of curiosity: A review and reinterpretation., Psychological bulletin, 116, 75 .

Loewenstein, G. (2000) Emotions in economic theory and economic behavior, American economic review, 90, 426-432.

Martinot, E. and Borg, N. (1998) Energy-efficient lighting programs: experience and lessons from eight countries, Energy policy, 26, 1071-1081.

Nath, V., Kumar, R., Agrawal, R., Gautam, A. and Sharma, V. (2013) Consumer adoption of green products: Modeling the enablers, Global business review, 14, 453-470.

Oster, E., Shoulson, I. and Dorsey, E. R. (2013) Optimal Expectations and Limited Medical Testing: Evidence from Huntington Disease, American Economic Review, 103, 804-830.

Oster, E. and Thornton, R. (2012) Determinants Of Technology Adoption: Peer Effects In Menstrual Cup Take-Up, Journal of the European Economic Association, 10, 1263-1293.

Price, M. K. (2014) Using field experiments to address environmental externalities and resource scarcity: major lessons learned and new directions for future research, Oxford Review of Economic Policy, 30, 621-638.

Reynolds, T. W., DeSisto, T. P., Murray, B. and Kolodinsky, J. (2007) Promoting energy efficiency in small island states: overcoming barriers to the adoption of compact fluorescent lighting in saint lucia, International Journal of Consumer Studies, 31, 460-467.

Roger, E. M. (1962) Diffusion of innovations., Diffusion of innovations.

Rogers, E. M. (2010) Diffusion of innovations, Simon and Schuster.

Romer, P. M. (1990) Endogenous technological change, Journal of political Economy, 98, S71-S102.

Roodman, D. (2009) Estimating fully observed recursive mixed-process models with cmp.

Roodman, D. (2011) Fitting fully observed recursive mixed-process models with cmp, Stata Journal, 11, 159-206(48). 
Schultz, P. W., Nolan, J. M., Cialdini, R. B., Goldstein, N. J. and Griskevicius, V. (2007) The Constructive, Destructive, and Reconstructive Power of Social Norms, Psychological Science, 18, 429-434.

Skinner, J. and Staiger, D. (2007) Technological diffusion from hybrid corn to beta blockers, Hard-to-Measure Goods and Services: Essays in Honor of Zvi Griliches. University of Chicago Press and NBER.

Spiegler, R. (2014) On the Equilibrium Effects of Nudging, Journal of Legal Studies.

Thornton, R. L. (2008) The demand for, and impact of, learning HIV status, The American economic review, 98, 1829-1863.

Train, K. E. (1998) Recreation demand models with taste differences over people, Land economics, pp. 230-239.

U.S. Chamber of Commerce Foundation (2012) Enterprising states: Policies that produce., https://www.uschamber.com/sites/default/files/documents/files/Enterprising-States-2012-web.pdf.

Van De Ven, N., Zeelenberg, M. and Van Dijk, E. (2005) Buying and selling exchange goods: Outcome information, curiosity and the endowment effect, Journal of Economic Psychology, 26, 459-468.

Volpp, K., Troxel, A. B., Pauly, M. V., Glick, H. A., Puig, A., Asch, D. A., Galvin, R., Zhu, J., Wan, F., DeGuzman, J., Corbett, E., Weiner, J. and Audrain-McGovern, J. (2009) A Randomized, Controlled Trial of Financial Incentives for Smoking Cessation, The New England Journal of Medicine, 360, 699-709.

Volpp, K. G., Levy, A. G., Asch, D. A., Berlin, J. A., Murphy, J. J., Gomez, A., Sox, H., Zhu, J. and Lerman, C. (2006) A randomized controlled trial of financial incentives for smoking cessation, Cancer Epidemiology and Prevention Biomarkers, 15, 12-18.

Yoeli, E., Hoffman, M., Rand, D. G. and Nowak, M. a. (2013) Powering up with indirect reciprocity in a large-scale field experiment., Proceedings of the National Academy of Sciences of the United States of America, 110 Suppl, 10424-9.

Young, A. (2005) Increasing returns and economic progress, in Readings In The Economics Of The Division Of Labor: The Classical Tradition, World Scientific, pp. 234-248.

Zanella, G. and Banerjee, R. (2016) Experiencing breast cancer at the workplace, Journal of Public Economics, 134, 53-66.

Zhe Jin, G., Kato, A. and List, J. A. (2010) Thats news to me! information revelation in professional certification markets, Economic Inquiry, 48, 104-122. 


\section{Appendices}

\section{Appendix A Additional Statistical evidence}

Tables A1, A2 and A3 show the estimated coefficients of ten linear probability models on the purchase decision analogous to the regression in Equation 1 of the form:

$$
y_{i j k}=Z_{i j k} \delta+\eta_{j}+\lambda_{k}+\varepsilon_{i j}
$$

where $y_{i j k}$ equals 1 if household $i$ located in suburb $j$ opened the door to salesperson $k$, and 0 otherwise. The vector $\mathrm{Z}$ includes indicators for: $i$ ) $\mathrm{W}$ and $\mathrm{OO}$ treatments (columns 1 and 2), ii) $\mathrm{L}$ and $\mathrm{H}$ treatments (columns 3 and 4), iii) high price (columns 5 and 6), iv) all treatments (columns 7 and 8) and $v$ ) all treatments and interaction terms between high price and L and H pressure level (columns 9 and 10), while the vector $\eta$ includes salesperson specific dummy variables and the vector $\lambda$ town-specific dummies. Moreover, clustered robust standard errors are included at date-solicitor time blocks level in order to control for possible randomization fixed effects. Table A1 shows results for the sample of 8815 households unconditional to answer the door, table A2, shows findings for the samples of 2848 households conditional to answer the door and finally the last table shows results for the sample of 290 households who purchased at least 1 pack of CFLs. 


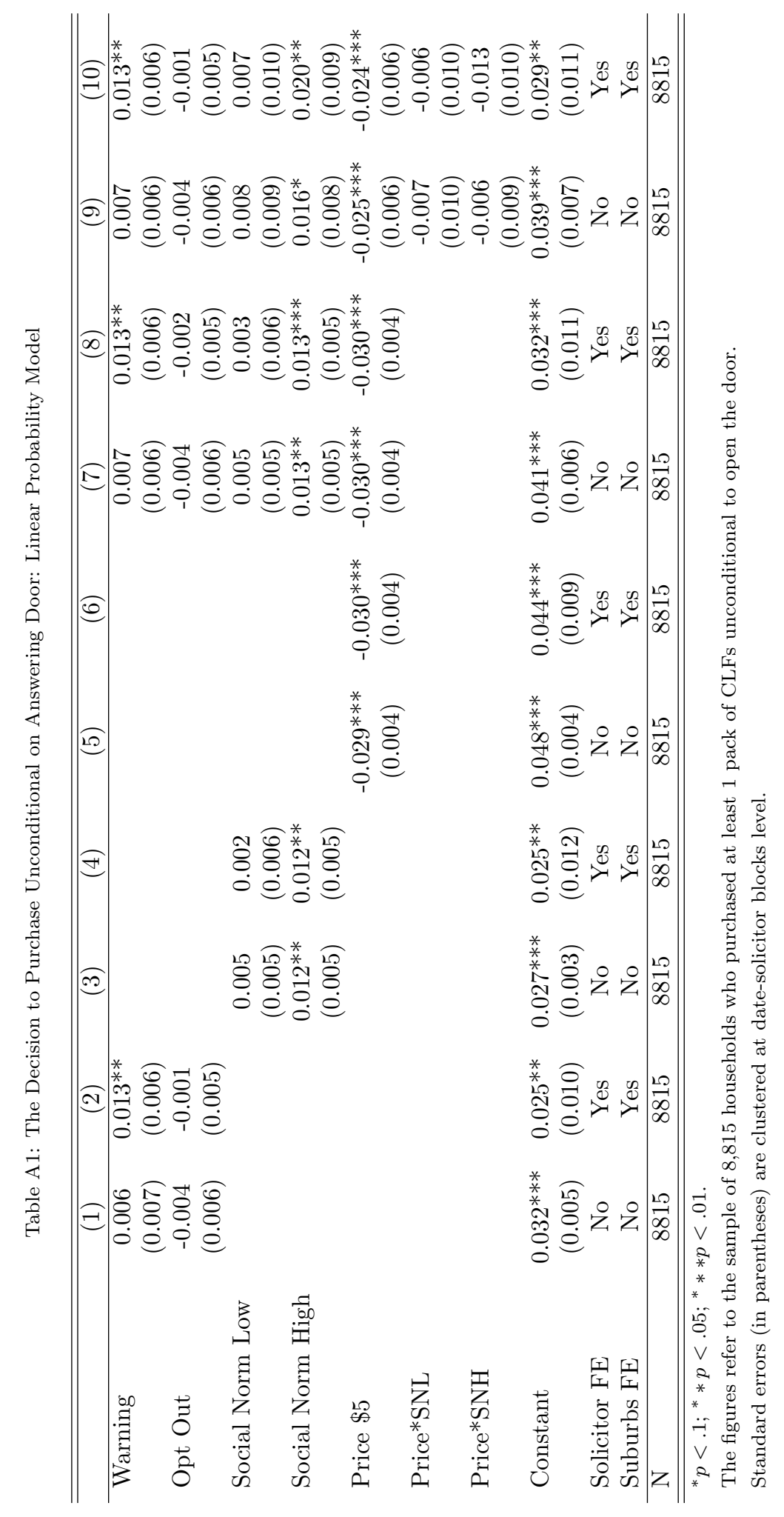




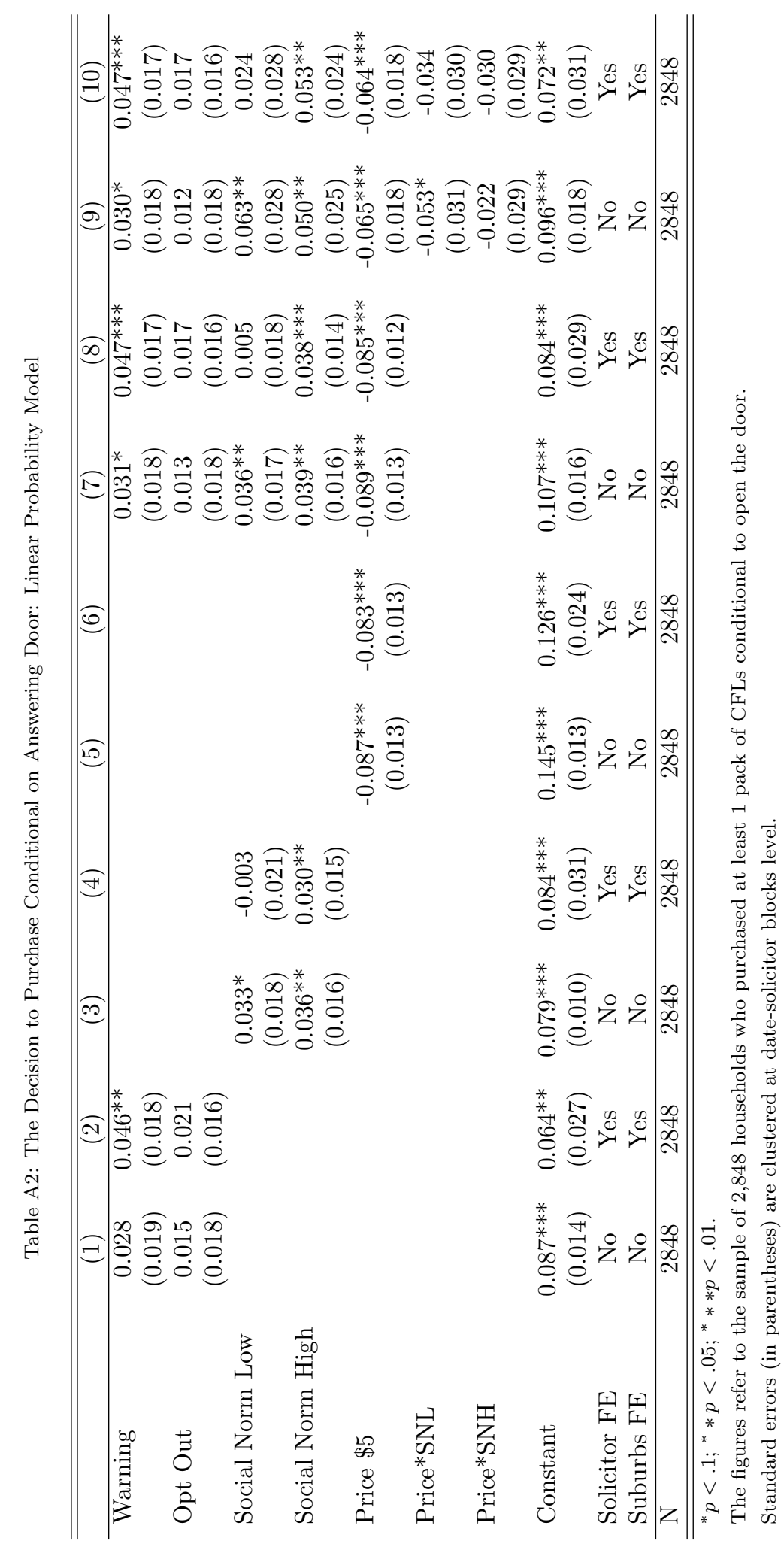




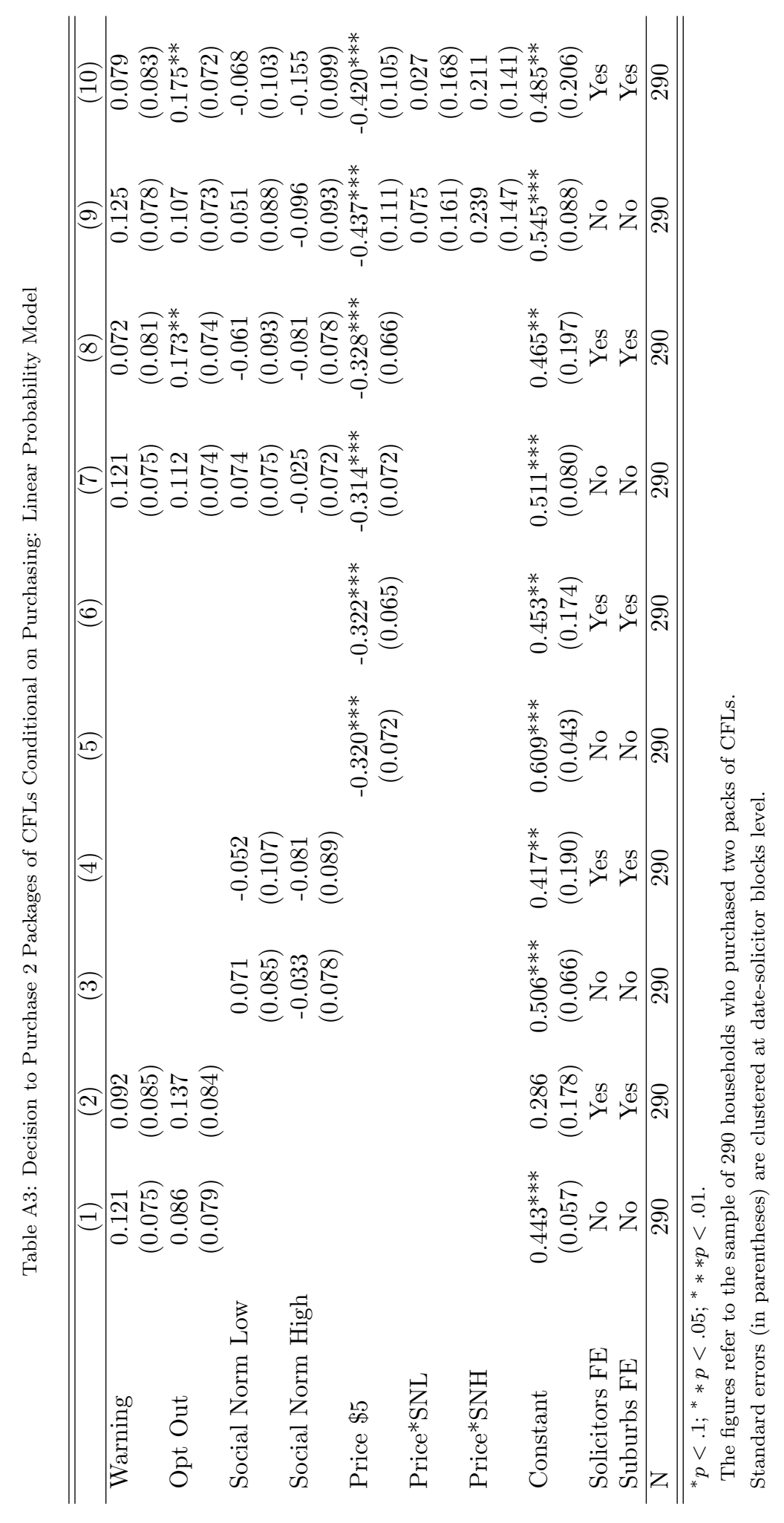




\section{Appendix B Solution of the structural model}

In our structural model, households' decisions are framed by way of a multi-stage game with incomplete information, where the individual -call her "Anna"- interacts at each stage with her "future selves" of which, at the time she has to make prior decisions along the sequence, she has limited knowledge. Information sets consist of what Anna knows about the 3 treatment interventions: $i$ ) the warning level $\omega \in\{N W, W, O O\}$; ii) the social pressure $s \in\{N, L, H\}$; and iii) the price $p \in\{1,5\}$. Similarly, Anna has partial information about her own realization of the three behavioral parameters of our structural model: $i$ ) $\alpha$ (which measures the combination of private benefits from CFLs and altruism), $i i) \varsigma$ ("sensitivity to social norms") and $i i i$ ) $\theta$ ("curiosity"). In this respect, we assume that Anna comes to know the realization of her own behavioral parameter only when the latter directly affects her choice, while prior decisions are made conditional on the expectation of the behavioral parameter(s) in object.

To summarize, these are the information sets characterizing our Bayesian game. Let $h_{k} \in H$ denote Anna's information set at stage $k=1, \ldots, 4$, where

1. $h_{1}=\left\{w, \mu_{\alpha}, \sigma_{\alpha}, \mu_{\varsigma}, \sigma_{\varsigma}, \theta, \rho\right\}$,

2. $h_{2}=h_{1}$,

3. $h_{3}=h_{2} \bigcup\{p, s, \varsigma\}$,

4. $h_{4}=h_{3} \bigcup\{\alpha\}$.

We solve the model "backwards", starting from Stage 4, using the standard notation of dynamic Bayesian games by conditioning payoffs upon the information available at each stage. Let $u_{h}(a)$ and $u_{h}^{h^{\prime}}(a)$, denote the "true" utility of action $a_{h} \in\{0,1\}$, i.e. the one directly affecting the likelihood function, and its expectation conditional on the information available at stage $h^{\prime}<h$, respectively. By the same token, $\beta_{h}\left(\beta_{h}^{h^{\prime}}\right)$ are Anna's "true" behavioral strategy (its expectation formulated at stage $h^{\prime}<h$, modeling Anna's beliefs over her own future behavior), respectively. ${ }^{29}$

\footnotetext{
${ }^{29}$ Since, at each information set, Anna has only two available actions, we indicate with $\beta$ the probability of choosing $a_{h}=1$ in the corresponding Stage respectively.
} 
Stage 4: intensive margin: $a_{4} \in\{0,1\}$

In Stage 4 Anna's quantity decision $q=a_{4}+1$ is only affected by her altruism parameter, $\alpha$ :

$$
u_{4}(q)=(\alpha-p) q
$$

Let $\alpha^{\star}=\left\{\alpha: u_{4}(1)=u_{4}(2)\right\}$ be the value of $\alpha$ that makes Anna indifferent with respect to her quantity decision, i.e., $\alpha^{\star}=p$. This, in turn, implies that, in Stage 4, Anna is indifferent over her quantity choice when $\alpha=\alpha^{\star}=p$ and that $\beta_{4}(\alpha)=1\left(\beta_{4}(\alpha)=0\right)$ when $\alpha>\alpha^{\star}\left(\alpha<\alpha^{\star}\right)$, respectively.

\section{Stage 3: extensive margin: $a_{3} \in\{0,1\}$}

Let $u_{3}\left(a_{3}\right)$ be Anna's "direct" utility evaluated at Stage 3 . If Anna decides not to buy anything (i.e., $a_{3}=0$ ), her utility will be $u_{3}(0)=-\varsigma-\gamma$, where $\gamma=0\left(\gamma=\gamma_{L}\right)\left[\gamma=\gamma_{H}\right]$ for $s=N(s=L)[s=H]$, respectively. The parameter $\varsigma$ captures the impact of social pressure that Anna experiences by being approached in person by Beppe. The level of social pressure, $\gamma$, is a function of the "proximity", referenced in the social norm, either $H$ or $L$. In this respect, we assume that the social pressure $s$ yields shift in the value of $\varsigma$, so that social pressure under treatment $s$ is $-\left(\varsigma+\gamma_{s}\right)$, where $\gamma_{s}=0\left(\gamma_{s}=\gamma_{L}\right)\left[\gamma_{s}=\gamma_{H}\right]$, depending on the assigned social norm $s=N(s=L)[s=H]$, respectively.

If Anna decides to buy something (i.e., $a_{3}=1$ ) her utility will be her expectation of her payoff at Stage 4 , i.e.,

$$
u_{3}(1)=\left(\alpha_{L}-p\right)\left(1-\beta_{4}^{3}\right)+2\left(\alpha_{H}-p\right) \beta_{4}^{3},
$$

where $\alpha_{L}=\int_{-\infty}^{p} x \psi_{\alpha}(x) d x$ and $\alpha_{H}=\int_{p}^{-\infty} x \psi_{\alpha}(x) d x$ are the conditional means of the values for the intensive marginal purchase in Stage 4 evaluated at Stage 3 and $\psi_{\alpha}(\cdot)$ is any smooth density function (not necessarily the normal distribution used in the structural estimations of Section 5).

Clearly, $u_{3}(1)$ is increasing in $\mu_{\alpha}$. By analogy with Stage 4 , let $\varsigma^{*}=\left\{\varsigma \in \Re: u_{3}(1)=u_{3}(0)\right\}=-\gamma-u_{3}(1)$ be the value of $\varsigma$ for the (extensive) marginal buyer. Therefore, $\varsigma^{\star}$ is decreasing in $\mu_{\alpha}$ and a positive social norm yields a downward shift of $\varsigma^{*}$, for all smooth densities $\psi_{\alpha}(\cdot)$. 


\section{Stage 2: choosing whether opening the door $a_{2} \in\{0,1\}(\omega \neq N W)$}

Before answering the door, Anna does not know her treatment assignment in Stage 2 over the price $p \in\{1,5\}$ and the social norm $s \in\{N, L, H\}$ randomization. In this respect, consistently with our assumption regarding the behavioral parameters, we shall assume that Anna knows that her treatment assignment is the result of two uniform i.i.d. draws from the corresponding supports. This, actually, corresponds to the implementation of the randomization over our treatment conditions. Then, her expected utility $u_{3}^{2}\left(a_{2}\right)$ can be derived as follows:

$$
\begin{aligned}
& u_{3}^{2}(0)=\frac{1}{3} \times \sum_{s} u_{h_{3}^{s}}(0)=\frac{1}{3} \sum_{s} E\left[u_{3}(0) \mid s\right] \\
& u_{3}^{2}(1)=\frac{1}{2} \times \sum_{p} u_{h_{3}^{p}}(1)=\frac{1}{2} \sum_{p} E\left[u_{3}(1) \mid p\right]
\end{aligned}
$$

Note that, if $\theta$ and $\varsigma$ are correlated, Anna could use her information about $\theta$ to infer information about ๙. However, we assume that Anna behaves as if she believes as if $\theta$ and $\varsigma$ were uncorrelated. Because of that, Anna's beliefs over her decisions in Stage 3 are evaluated using the same methodology we used to evaluate her beliefs over her decision in Stage 4. We define this assumption - which is needed to avoid the implicit fixed point problem for which beliefs over Stage 3 are needed to evaluate optimal behavior in Stage 2 - although behavior in Stage 2 and 3 is estimated simultaneously- as the independence bias assumption (IB). Once we allow for IB, the analysis of Stage 2 is straightforward, namely:

$$
\begin{gathered}
u_{2}(0)=0 ; \\
u_{2}(1)=\left(1-\beta_{3}^{2}\right) u_{3}^{2}(0)+\beta_{3}^{2} u_{3}^{2}(1)+\theta .
\end{gathered}
$$

Therefore, by analogy of Stages 3 and 4 we can identify a threshold $\theta^{*}=-\left(1-\beta_{3}^{2}\right) u_{3}^{2}(0)-\beta_{3}^{2} u_{3}^{2}(1)$, for each warning level $\omega \in\{W, O O\}$, such that Anna answers the door if and only if $\theta \geq \theta^{*}$.

\section{Stage 1: choosing whether to check the flyer $a_{1} \in\{0,1\}(\omega=O O)$}

In our experimental design, we include a treatment (OO) which allows for Anna to "opt out" without any cost by simply marking a box on the flyer. This decision is only relevant for those in the OO treatment. In 
this case, Anna decides not to check the box if $\theta \geq \theta^{*}$. 